Article

\title{
A Risk Aversion Dispatching Optimal Model for a Micro Energy Grid Integrating Intermittent Renewable Energy and Considering Carbon Emissions and Demand Response
}

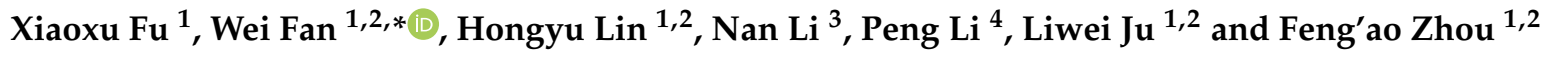 \\ 1 School of Economics and Management, North China Electric Power University, Beijing 102206, China; \\ fuxiaoxu2008@126.com (X.F.); hone@ncepu.edu.cn (H.L.); hdlw_ju@ncepu.edu.cn (L.J.); \\ zhoufengao@ncepu.cn (F.Z.) \\ 2 Beijing Energy Development Research Base, Beijing 102206, China \\ 3 State Grid Qinghai Electric Economical Research Institute, Beijing 100045, China; Inan0514@qh.sgcc.com.cn \\ 4 State Grid Henan Economical Research Institute, Zhengzhou 450052, China; hdlp0830@163.com \\ * Correspondence: fanwei@ncepu.edu.cn; Tel.: +86-159-3212-9195
}

Received: 4 November 2019; Accepted: 25 November 2019; Published: 3 December 2019

check for updates

\begin{abstract}
This paper focuses on an optimal schedule for a micro energy grid considering the maximum total carbon emission allowance (MTEA). Firstly, the paper builds an energy devices operation model and demand response (DR) model. Secondly, to maximize the economical operation revenue, the basic scheduling model for the micro energy grid is constructed. Thirdly, the conditional value at risk method and robust stochastic theory are introduced to describe the uncertainty of wind power, photovoltaic power, and load, and a risk aversion model is proposed. Finally, this paper selects the Xinxiang active distribution network demonstration project in Jining, China as an example. The results show that: (1) a micro energy grid can make the most use of the complementary characters of different energy sources to meet different energy demands for electricity, heat, cold, and gas; (2) the risk aversion scheduling model can represent the influence of uncertainty variables in objective functions and constraints, and provide a basis for decision makers who have different attitudes; and (3) DR can smooth the energy load curves. MTEA can enhance the competitiveness of the clean energy market, thus promoting the grid-connected generation of clean energy. Therefore, the risk aversion model can maximize the economic benefits and provide a basis for decision makers while rationally controlling risks.
\end{abstract}

Keywords: micro energy grid; distributed energy; uncertainty; risk aversion; demand response

\section{Introduction}

In recent years, environmental pollution and the current depletion of fossil energy have become more and more serious. The energy structure should be transformed and upgraded urgently. It is the current trend of the energy field to pursue the efficient use, clean environmental protection, and sustainable development of energy [1]. As a further extension of micro power grids, a micro energy grid could realize the coordinated planning and unified scheduling of multiple energy sources (electricity, heat, cold, and gas, etc.) through new energy technologies and internet technologies, which could effectively improve energy efficiency while achieving local production and consumption of energy [2]. The China Development and Reform Commission also put forward the Guiding Opinions on the Development of "Internet + Promoting" Intelligent Energy, pointing out that it is essential to strengthen 
the construction of multi-energy synergistic integrated energy networks, and the coupling interactions and comprehensive utilization of different energy types, such as electricity, gas, heating, and cooling [3].

In recent years, micro energy grids have attracted widespread attention and practical development. The smart polygeneration microgrid (SPM) project of the University of Genoa for the Savona campus involves multiple electric, thermal, and combined heating and power generators [4]. Cassel University integrated a wind turbine, $\mathrm{PV}$, biogas power station and hydro power plant into a micro energy grid (MEG) [5]. In 2014, the Xiaozhongdian wind-photovoltaic (PV)-hydro distributed demonstration project of the China National Electric Power Group Corporation successfully connected to the grid in Yunnan province [6]. The La Plata University in Finland is developing a $40 \mathrm{~m}$ diameter straight-leaf vertical shaft wind turbine that drives an oil-fired heating system for greenhouse heating [7]. The pilot projects of wind power heating in Linxi County and Zha'rutqi of the Inner Mongolia Autonomous Region have been operational for three years, and the annual consumption of wind power is approximately 149 million $\mathrm{kW} \cdot \mathrm{h}[8]$.

The operation mechanism and scheduling operation of micro energy grids have always been hotspots for research, both at home and abroad. On the premise of meeting the security constraints, the micro energy grid uses different objectives to rationally arrange the operation of energy equipment within the micro energy grid. Zhang et al. [9] constructed a micro energy grid operation optimization mode taking the minimum daily operating cost as the target. Du et al. [10] introduced modeling, planning and optimization methods for a regional integrated energy system. Luo [11] established a model for minimizing the sum of various costs and analyzed the integrated energy system with P2G. The above reference considered the objectives and related constraints of the micro energy grid, but the proposed models were used to analyze the uncertainty of the distributed energy. In fact, the uncertainty will affect the coordinated supply of multi-energy loads, such as electricity, heating, cooling, and gas, in the grid.

The uncertainty of distributed energy in a micro-energy network is mainly reflected in the volatility of wind power plants (WPP) and PV output power. A key issue for MEG operation is how to use units, storage devices, electric vehicles, and load, to balance random changes of wind and solar units, to guarantee the steady output of the MEG. Peik-Herfeh et al. [12] used the two-point estimation theory to take an estimate point on both sides of the forecast value to represent the unit output variability. Yang et al. [13] gained distribution parameters based on the characteristic that the wind speed obeys a Weibull distribution. Zamani et al. [14] used a stochastic program to handle electricity price uncertainty and studied a virtual power plant bidding model considering the uncertainty. Tan et al. [15] constructed an economical dispatching model considering the output power volatility of clean energy, based on a chance-constrained program. The above related research mainly considered uncertain variables as random variables and constructed stochastic dispatching optimization models by using stochastic modeling methods, such as stochastic programming and robust optimization. The validity of the method was verified by actual cases.

The above research shows that the existing research about micro energy grids focuses on system modeling, optimal operation, and uncertainty analysis. However, in uncertainty analysis, a stochastic program describes the uncertainty with stochastic variables. Based on the probability distribution of stochastic variables, system constraints are described as opportunistic constraints [16]. However, whether DERs with a small capacity and large quantity have statistical characters needs to be checked. The accurate establishment of information collection and a probability distribution function is difficult. The optimal solution sets of robust optimization have a certain degree of restraint on the effects. Adjusting the size of a coefficient can determine the dispatching scheme, which can restrain the influence of uncertainty to different degrees [17]. At the same time, the existing research results are more focused on the processing of constraints with uncertain variables, lacking consideration of the objective function processing method with uncertain variables. Conditional value at risk (CVaR) can quantitatively represent the uncertainty risk of the objective function. By combining it with robust stochastic optimization theory, a relatively complete risk decision model can be constructed. According 
to the above analysis, an optimal dispatching model for a MEG is put forward. The main contributions are as follows:

- This paper designs a novel structure for a micro energy grid optimal operation containing production devices, conversion devices, and storage devices, depending on the demand response and carbon emissions. The effects of price-based demand response (PBDR) and incentive-based demand response (IBDR) on different energy load curves are compared and analyzed. The optimization effect of the maximum total emission allowance (MTEA) on the MEG operation is also analyzed.

- This paper establishes a basic dispatching model for the micro energy grid considering different constraints, selecting maximizing operating revenue as the objective function of the MEG operation with the constraints of load power balance, equipment operation, DR operation, maximum carbon emissions, and rotating standby.

- This paper puts forward a risk aversion model for the micro energy grid on the basis of the CVaR method and robust stochastic optimization theory. The CVaR method mainly describes the influence of uncertainty factors of the objective function, and robust stochastic optimization theory converts constraints with uncertainty variables to provide an optimal basis for decision makers.

The structure of the paper is as follows: Section 2 designs a core structure for the micro energy grid and establishes an operation model of the equipment and DR operation model. Section 3 constructs the basic scheduling model of the micro energy grid without considering uncertainty, which takes maximizing the operational benefit as the optimization objective. Furthermore, a risk aversion model of the micro energy grid is established on the basis of CVaR and robust stochastic optimization theory in Section 4. Finally, Section 5 selects the China Jining Xinxiang Active Distribution Network Demonstration Project as an example object to verify the effectiveness and applicability of the model. Section 6 outlines the contributions and conclusions.

\section{MEG Description and Output Model}

This paper designs the basic structure of the micro energy grid and builds the energy devices operation model and demand response (DR) model.

\subsection{Structure Description}

The micro energy grid includes energy production, conversion, storage equipment, and energy consumers. Energy production equipment includes the wind power plant (WPP), photovoltaic power generation (PV) and conventional gas turbine (CGT). Energy conversion equipment includes power-to-gas (P2G), power to heating (P2H), heating to cooling (H2C), and power to cooling (P2C). Energy storage equipment includes a gas storage tank (GS), power storage battery (PS), heat storage tank (HS), and cold storage tank (CS). At the same time, in order to motivate users under a flexible load to participate in the optimal operation of the MEG, the price-based demand response (PBDR) and incentive-based demand response (IBDR) are implemented. The former is used to guide terminal users to use electricity reasonably through the performance of a differentiated time-of-use price, while the IBDR is mainly used to provide an emergency energy supply to the MEG. In the MEG, power electronics converters are required for some voltage adaptations-for instance, the PV generation-and the type of grid is AC. All the power from different devices must be converted into AC. Figure 1 shows the structure of the micro energy grid. 


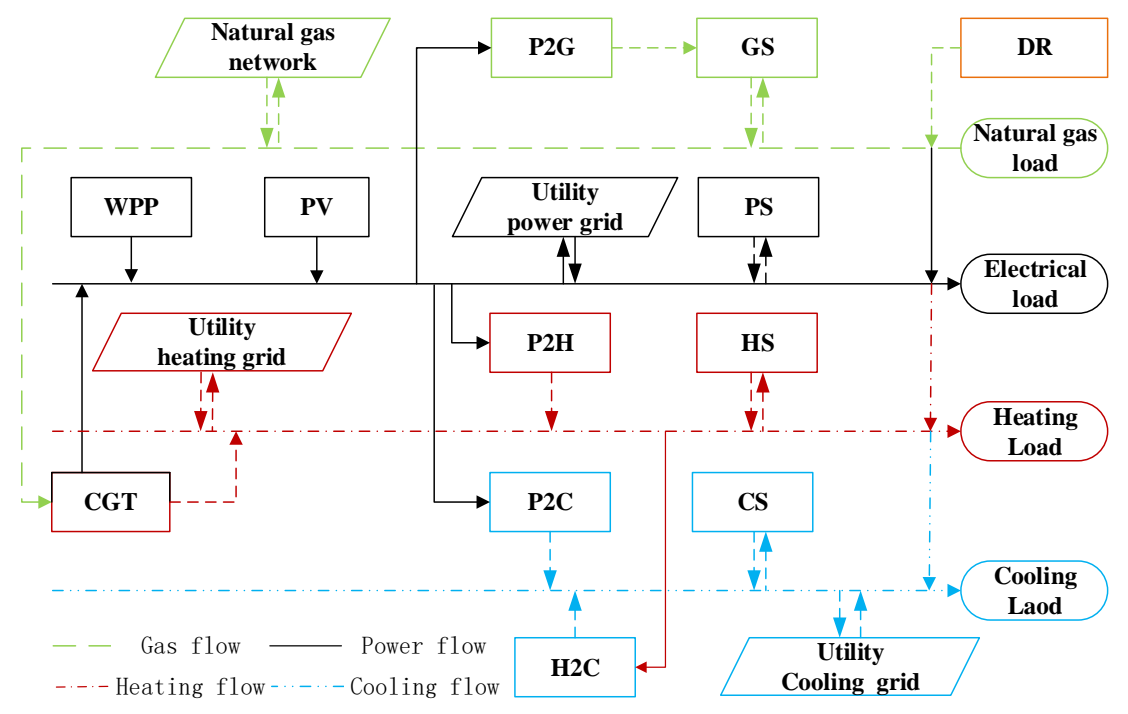

Figure 1. Structure of the micro energy grid.

According to Figure 1, MEGs are connected with an upper power grid, gas grid, heat grid and cold grid. An MEG can interact with upper energy grids. When there is excess energy in MEGs, it can be sold to upper energy grids to obtain economic benefits. Conversely, when the internal energy of an MEG is insufficient, energy will be bought from superior energy grids. Because the real-time price of different energy is different, the MEG will reasonably choose the energy sale or purchase scheme according to the different prices of electricity, heating, cooling, and gas, so as to achieve the goal of maximizing operating benefit. However, the output power of WPP and PV has strong uncertainty and high environmental economics. Therefore, maintaining the balance of the operational benefit and risk will be a key issue for formulating the optimal operation plan of the MEG.

\subsection{Energy Devices Operation Model}

The energy devices operation model includes the energy production (EP) operation model, energy conversion (EC) operation model and energy storage (ES) operation model.

\subsubsection{EP Operation Model}

EP equipment contains WPP, PV, and CGT. WPP is decided by the wind speed and PV is decided by the solar radiation, while CGT mainly produces heat vapor by consuming natural gas for the power supply and heat supply. Generally speaking, CGT includes two types: following thermal load (FTL) and following electric load (FET). This paper sets CGT to operate in FTL mode. The output models of different devices are as follows:

(1) WPP operation model

Wind power generation is determined by the wind speed. The WPP generation output is calculated according to the real-time wind speed and fan parameters:

$$
g_{W P P, t}^{*}=\left\{\begin{array}{l}
0, \quad v_{t} \leq v_{\text {in }} \\
\frac{v-v_{\text {in }}}{v_{R}-v_{\text {in }}} g_{R}, v_{\text {in }} \leq v_{t} \leq v_{R} \\
g_{R}, \quad v_{R} \leq v_{t} \leq v_{\text {out }} \\
0, \quad v_{t} \geq v_{\text {out }}
\end{array}\right.
$$


(2) PV output model

PV power generation is determined by the solar photovoltaic radiation. On the basis of photoelectric conversion principles, PV output power is calculated as follows:

$$
g_{P V, t}^{*}=\eta_{P V} \times S_{P V} \times \theta_{t}
$$

\section{(3) CGT output model}

When natural gas enters the gas turbine combustion chamber, it generates hot steam to drive the turbine to work by combustion, and the exhausted hot gas can provide heating energy to users through a heat recovery device. As for the principle of the gas turbine, existing research is very mature [18]. This paper directly quotes power and heating supply models in reference [19]. The specific model is as follows:

$$
\begin{gathered}
g_{C G T, t}=V_{C G T, t} H_{n g} \eta_{C G T, t} \\
Q_{C G T, t}=V_{C G T, t}\left(1-\eta_{C G T, t}-\eta_{l o s s}\right) \eta_{h r}
\end{gathered}
$$

\subsubsection{EC Operation Model}

EC mainly includes power-to-gas (P2G), power-to-cooling (P2C), power-to-heat (P2H), and heat-to-cooling $(\mathrm{H} 2 \mathrm{C})$ convertors. The operating power model of various types of EC equipment has already been constructed in our previous works [19].

\section{(1) P2G device}

P2G can utilize the curtailment output of WPP and PV to convert $\mathrm{CO}_{2}$ into $\mathrm{CH}_{4}$, which realizes the interconnection of the power grid and gas network. P2G is divided into two processes: electrolysis and methanation. Electrolysis uses excess electricity to generate hydrogen by electrolyzing water and injecting it into the natural gas pipeline or a storage device. On the basis of electrolysis, the methanation process uses the hydrogen to react with carbon dioxide to form methane and water under the action of a catalyst. Figure 2 shows the technical principles of P2G-GS operation.

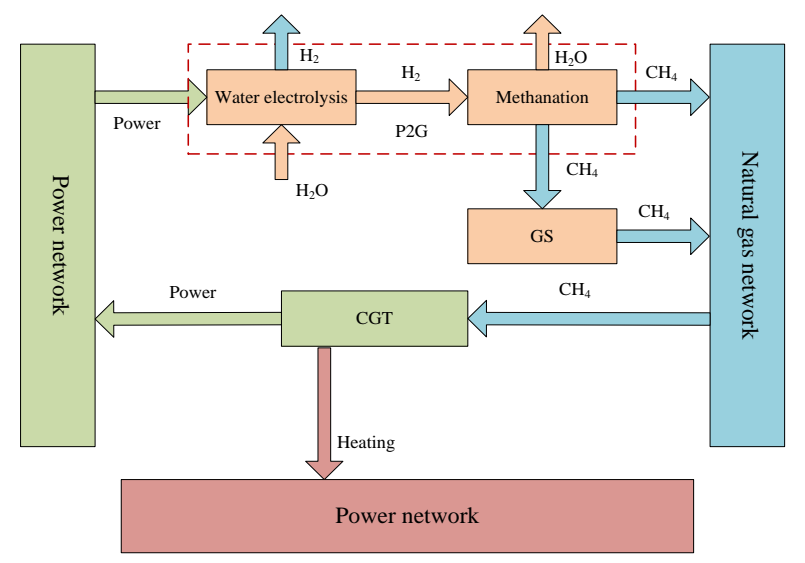

Figure 2. Technical principles of P2G-GS operation.

The $\mathrm{CH} 4$ generated by P2G can be injected into a natural gas network, conventional gas turbines (CGT), gas boilers (GB), and a gas storage tank (GST). The detailed operation model is as follows:

$$
V_{P 2 G, t}=g_{P 2 G, t} \eta_{P 2 G} / H_{n g}
$$

Furthermore, the proportions of natural gas generated by P2G and injected into the CGT, GS and natural gas network are $\eta_{P 2 G, t^{\prime}}^{C G T} \eta_{P 2 G, t^{\prime}}^{G S}$ and $\eta_{P 2 G, t^{*}}^{N G}$ 
(2) Other devices

There is a certain efficiency in the conversion between different energies. Although the efficiency is not constant, it usually does not change much when the equipment runs steadily. According to reference [20], it can be regarded as constant. The mathematical model of the energy conversion unit is expressed as:

$$
\left[\begin{array}{c}
V_{P 2 G, t} \\
Q_{P 2 C, t} \\
Q_{P 2 H, t} \\
Q_{H 2 C, t}
\end{array}\right]=\left[\begin{array}{cccc}
g_{P 2 G, t} & 0 & 0 & 0 \\
0 & g_{P 2 C, t} & 0 & 0 \\
0 & 0 & g_{P 2 H, t} & 0 \\
0 & 0 & 0 & Q_{H 2 C, t}
\end{array}\right]\left[\begin{array}{c}
\eta_{P 2 G} \\
\eta_{P 2 C} \\
\eta_{P 2 H} \\
\eta_{H 2 C}
\end{array}\right]
$$

\subsubsection{ES Operation Model}

ES mainly includes power storage (PS), heat storage (HS), cooling storage (CS), and gas storage (GS). According to the relevance between the energy supply and energy demand, different types of energy storage equipment can use their own energy storage facilities to store and release energy. The specific operation model is as follows:

$$
S_{E S, t}=\left(1-\eta_{E S, t}^{\text {loss }}\right) S_{E S, t-1}+\left[E S_{t}^{\text {input }} \eta_{E S}^{\text {input }}-E S_{t}^{\text {output }} / \eta_{E S}^{\text {output }}\right]
$$

\subsection{DR Operation Model}

The DR operation model mainly includes the price-based demand response (PBDR) operation model and the incentive-based demand response (IBDR) operation model.

\subsubsection{PBDR Operation Model}

The PBDR guides the terminal users to use energy reasonably by implementing a peak-valley time-of-use price, which can realize "peak-cutting and valley-filling". According to microeconomic principles, the PBDR can be calculated by the price elasticity of demand [10], as follows:

$$
E_{s t}=\frac{\Delta L_{s} / L_{s}^{0}}{\Delta P_{t} / P_{t}^{0}}\left\{\begin{array}{l}
E_{s t} \leq 0, s=t \\
E_{s t} \geq 0, s \neq t
\end{array}\right.
$$

where when $s=t, E_{s t}^{e, h, c}$ is self-elasticity; when $s \neq t, E_{s t}^{e, h, c}$ is cross-elasticity. Correspondingly, the change of energy demand load after PBDR is calculated as follows:

$$
L_{t}^{a f t e r}=L_{t}^{\text {before }} \times\left\{E_{t t} \times \frac{\left[P_{t}^{a f t e r}-P_{t}^{\text {before }}\right]}{P_{t}^{\text {before }}}+\sum_{\substack{s=1 \\ s \neq t}}^{24} E_{s t} \times \frac{\left[P_{s}^{\text {after }}-P_{s}^{\text {before }}\right]}{P_{s}^{\text {before }}}\right\}
$$

where $\Delta L_{t}^{a f t e r}$ indicates the amount of load change after PBDR.

\subsubsection{IBDR Operation Model}

The IBDR is signed by the MEG operator and terminal users in advance. When emergency energy demand occurs, the operator can directly control the energy usage behavior of the terminal users and give some financial compensation. According to reference [10], demand response providers (DRPs) are involved in the demand response stage by stage, mainly on the basis of different energy prices. Therefore, the operation of DRPs should meet the following principles:

$$
\begin{gathered}
D_{i}^{k, j, \min } \leq \Delta L_{i, t}^{k, j} \leq D_{i, t}^{k, j}, j=1 \\
0 \leq \Delta L_{i, t}^{k, j} \leq\left(D_{i, t}^{k, j}-D_{i, t}^{k, j-1}\right), j=2,3, \ldots, J
\end{gathered}
$$




$$
\Delta L_{t}^{k, I B}=\sum_{i=1}^{I} \sum_{j=1}^{J} \Delta L_{i, t}^{k, j}
$$

\section{Basic Dispatching Model of the Micro Energy Grid}

The section covers the construction of the basic scheduling optimal model for the micro energy grid, aimed at maximizing the economic revenue of operation considering the constraints of the energy power balance, device operation, and system reserve balance.

\subsection{Objective Functions}

The micro energy grid is mainly supplied by WPP, PV and CGT. Through conversion and storage equipment, it can meet electricity, heating, cooling and gas load demands together. WPP and PV have the characteristics of a low marginal cost of power generation and zero emissions of pollution. This paper chooses maximizing the operating revenue as the operational optimization goal of the MEG. The specific objective function is as follows:

$$
\max R=\sum_{t=1}^{24}\left\{R_{E P, t}+R_{E C, t}+R_{E S, t}+R_{D R, t}+R_{C a r b o n, t}\right\}
$$

The remaining carbon emission rights can be traded externally when the carbon emissions of the MEG are less than the maximum emission trade allowance (META). For EP, the operating revenue is equal to the energy supply income minus the energy supply cost. The energy supply revenue is equal to the product of the electricity quantity and its price. The marginal cost of WPP and PV is basically close to zero. The energy supply cost of CGT includes the fuel consumption cost and start-stop cost, which is calculated as follows:

$$
\begin{aligned}
C_{C G T, t} & =C_{C G T, t}^{\text {fuel }}+C_{C G T, t}^{s d} \\
& =\left\{\begin{array}{c}
a\left(g_{C G T, t}+\theta_{h}^{e} Q_{C G T, t}\right)^{2}+ \\
b\left(g_{C G T, t}+\theta_{h}^{e} Q_{C G T, t}\right)+c
\end{array}\right\}+\left\{\begin{array}{c}
{\left[\mu_{C G T, t}^{u}\left(1-\mu_{C G T, t-1}^{u}\right)\right] C_{C G T, t}^{u}+} \\
{\left[\mu_{C G T, s}^{d}\left(1-\mu_{C G T, s+1}^{d}\right)\right] C_{C G T, s+1}^{d}}
\end{array}\right\}
\end{aligned}
$$

For EC and ES, the operating revenue is equal to the energy output (energy release) income minus the energy input (energy storage) cost. The calculation is as follows:

$$
R_{E C(S), t}=Q_{E C(S), t}^{\text {output }} p_{E C(S)}^{\text {output }} \eta_{E C(S)}^{\text {output }}-Q_{E C(S), t}^{\text {input }} p_{E C(S)}^{\text {input }} / \eta_{E C(S)}^{\text {input }}
$$

For DR, operation revenue includes PBDR income and IBDR income. The former can increase the energy supply, while the latter is mainly to reduce the penalty cost of a power shortage. The calculation is as follows:

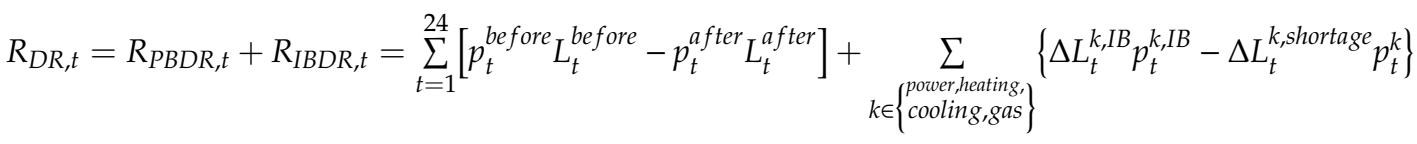

$$
\begin{aligned}
& R_{\text {Carbon }, t}=\left\{\left[a_{C G T}+b_{C G T}\left(g_{C G T, t}+\theta_{h}^{e} Q_{C G T, t}\right)+c_{C G T}\left(g_{C G T, t}+\theta_{h}^{e} Q_{C G T, t}\right)^{2}\right]-Q_{M T E A, t}\right\} p_{C a r b o n, t}
\end{aligned}
$$

\subsection{Condition Constraints}

To achieve an optimal supply of electricity, heating and cooling, it is necessary to comprehensively consider the energy supply and demand balance constraint, EP, EC, ES operation constraint, and system rotation reserve constraint of MEGs. The specific constraints are as follows:

(1) Energy supply and demand balance constraint 


$$
\begin{gathered}
g_{C G T, t}+g_{W P P, t}+g_{P V, t}+g_{P S, t}^{\text {output }}+g_{P 2 G, t}^{\text {output }}+g_{U P G, t}=L_{t}^{e}+g_{E S, t}^{\text {input }}+g_{P 2 G, t}^{\text {input }}+g_{P 2 H, t}^{\text {input }}+g_{P 2 C, t}^{\text {cinput }}+\Delta L_{t}^{p, P B}+\Delta L_{t}^{p, I B} \\
Q_{C G T, t}+Q_{P 2 H, t}^{\text {output }}+Q_{H S, t}^{\text {output }}+Q_{U H G, t}=L_{t}^{h}+Q_{H S, t}^{\text {input }}+Q_{H 2 C, t}^{\text {input }}+\Delta L_{t}^{h, P B}+\Delta L_{t}^{h, I B} \\
Q_{P 2 C, t}^{\text {output }}+Q_{H 2 C, t}^{\text {output }}+Q_{C S, t}^{\text {output }}+Q_{U C G, t}=L_{t}^{c}+Q_{C S, t}^{\text {input }}+\Delta L_{t}^{c, P B}+\Delta L_{t}^{c, I B}
\end{gathered}
$$

(2) CGT operation constraints

For CGT, the relevance of the power generation and heating supply power is called the "electrical heating character." Under a given thermal power, the power generated has some adjustability. This is because under a given amount of steam extracted, CGT adjusts the output power of the entire steam turbine by adjusting the amount of condensation steam to generate electricity. However, the larger the amount of steam extracted, the smaller the proportion of condensing steam required to generate electricity, so the adjustment range is smaller. The specific constraints are as follows:

$$
\begin{gathered}
\max \left\{g_{C G T}^{\min }-c_{\min } Q_{C G T}, c_{m}\left(Q_{C G T}-Q_{C G T}^{0}\right)\right\} \leq g_{C G T} \leq g_{C G T}^{\max }-c_{\max } Q_{C G T} \\
u_{C G T, t} \Delta g_{C G T}^{-} \leq\left(g_{C G T, t}+\theta_{h}^{e} Q_{C G T, t}\right)-\left(g_{C G T, t-1}+\theta_{h}^{e} Q_{C G T, t-1}\right) \leq u_{C G T, t} \Delta g_{C G T}^{+}
\end{gathered}
$$

where $c$ is the reduction of power caused by extra extraction of the unit heating supply when the steam inlet amount is constant. $c_{m}=\Delta g_{C G T} / \Delta Q_{C G T}$ is the elasticity coefficient of electricity power and heating power under backpressure operation. $Q_{C G T}^{0}$ is a constant.

(3) EC operation constraints

EC includes P2H, P2C, H2C, and P2G. According to Equation (8), the energy conversion relevance of different devices can be established. Different energy conversion devices have their own power constraints; the details are as follows:

$$
\begin{gathered}
u_{P 2 G, t} V_{P 2 G, t}^{\min } \leq V_{P 2 G, t} \leq u_{P 2 G, t} V_{P 2 G, t}^{\max } \\
u_{E C, t}^{\text {output }} Q_{E C, t}^{\text {output,min }} \leq Q_{E C, t}^{\text {output }} \leq u_{E C, t}^{\text {output }} Q_{E C, t}^{\text {output } \max } \\
u_{E C, t}^{\text {input }} Q_{E C, t}^{\text {input,min }} \leq Q_{E C, t}^{\text {input }} \leq u_{E C, t}^{\text {input }} Q_{E C, t}^{\text {input,max }}
\end{gathered}
$$

(4) ES operation constraints

ESD includes ES, HS, CS, and GS. Energy storage capacity constraints should also be considered when various types of energy storage equipment store or release energy. The specific constraints are as follows:

$$
\begin{gathered}
S_{E S, t}^{\min } \leq S_{E S, t} \leq S_{E S, t}^{\max } \\
u_{E S, t}^{\text {output }} Q_{E S, t}^{\text {output,min }} \leq Q_{E S, t}^{\text {output }} \leq u_{E S, t}^{\text {output }} Q_{E S, t}^{\text {output } \max } \\
u_{E S, t}^{\text {input }} Q_{E S, t}^{\text {input } \min } \leq Q_{E S, t}^{\text {input }} \leq u_{E S, t}^{\text {input }} Q_{E S, t}^{\text {input,max }}
\end{gathered}
$$

(5) System reserve constraints

MEGs are set to operate according to the "following thermal load" mode, so some electrical load reserve capacity and cooling load reserve capacity need to be reserved. In addition, the randomness of WPP and PV also requires MEGs to reserve certain capacity. The specific constraints are as follows:

$$
\begin{gathered}
g_{M E G, t}^{p, \max }-g_{M E G, t}^{p}+g_{P S, t}^{\text {output }}+\left[L_{t}^{p, a f t e r}-L_{t}^{p, \text { before }}, 0\right]^{+}+\Delta L_{t}^{p, I B} \geq r_{p} L_{t}^{p}+r_{W P P}^{u p} g_{W P P, t}+r_{P V}^{u p} g_{P V, t} \\
g_{M E G, t}^{p}-g_{M E G, t}^{p, \min }+g_{P S, t}^{\text {input }}+\left[L_{t}^{p, a f t e r}-L_{t}^{p, \text { before }}, 0\right]^{-} \geq r_{W P P}^{d n} g_{W P P, t}+r_{P V}^{d n} g_{P V, t}
\end{gathered}
$$




$$
g_{M E G, t}^{c, \max }-g_{M E G, t}^{c}+g_{C S, t}^{\text {output }}+\left[L_{t}^{c, \text { after }}-L_{t}^{c, \text { before }}, 0\right]^{+} \geq r_{c} L_{t}^{c}
$$

(6) Other operation constraints

An MEG also needs to consider the operation constraints of PBDR and IBDR, including maximum output power constraints, start-stop time constraints, and uphill-downhill power constraints. CGT operation also needs to consider start-stop time constraints. The specific constraints are described in reference [10].

\section{Risk Aversion Model of the Micro Energy Grid}

To describe the uncertainty of the wind power plant (WPP), photovoltaic power generation (PV), and load, the conditional value at risk $(\mathrm{CVaR})$ method and robust stochastic optimization theory are introduced to construct a risk aversion model for the micro energy grid in this section.

\subsection{Uncertainty Factors Analysis}

There are three uncertainty factors in the proposed MEG, which are $g_{W P P, t}, g_{P V, t}$, and $L_{t}$. Simulating the uncertainty is the key to formulating an optimal dispatching strategy for the MEG. Generally speaking, the load demand mainly consists of two parts: the forecast value and the forecast deviation. Considering that the forecast deviation obeys a normal distribution, load demand can be calculated as follows:

$$
L_{t}=L_{t}^{f}+\Delta L_{t}^{e}
$$

where if $\Delta L_{t}^{e}$ obeys $\Delta L_{t}^{e} \sim\left[0, \delta_{L, t}^{2}\right], \delta$ is the load forecast standard deviation, then the load demand will obey $L_{t} \sim\left[L_{t}^{f}, \delta_{L, t}^{2}\right]$. In the proposed MEG, there are various flexible loads such as the electricity, heating, cooling and gas, and energy storage equipment, which can cope with load uncertainty, so this paper does not take the uncertainty of the load demand into account.

For WPP and PV, the uncertainty is mainly caused by the natural wind speed and photovoltaic radiation intensity. Simulating the natural wind and photovoltaic radiation intensity is the key to simulating uncertainty. Referring to [21], the Weibull and Beta distribution function can simulate the wind speed and photovoltaic radiation intensity respectively, as follows:

$$
\begin{gathered}
f(v)=\frac{\varphi}{\vartheta}\left(\frac{v}{\vartheta}\right)^{\varphi-1} e^{-(v / c)^{\varphi}} \\
f(\theta)= \begin{cases}\frac{\Gamma(\omega) \Gamma(\psi)}{\Gamma(\omega)+\Gamma(\psi)} \theta^{\omega-1}(1-\theta)^{\psi-1}, & \text {, otherwise } \\
0 & \text {, } 0 \leq 1, \omega \geq 0, \psi \geq 0\end{cases}
\end{gathered}
$$

This obtains the distribution function of the above uncertainty factors, which allows us to analyze the uncertainty factors of the MEG. This paper uses the conditional risk at value method and robust stochastic optimization theory to describe the uncertainty factors of the objective function and constraints, respectively, and constructs the risk avoidance optimization model, which provides a basis for decision makers who have different risk attitudes, so that they can properly formulate optimal scheduling strategies.

\subsection{Risk Aversion Optimal Model}

The conditional value at risk method is used to represent the uncertainty factors of the objective function in this paper. Compared with the traditional value at risk (VaR) method, it can represent a risk distribution situation at the exterior of the confidence level, which is helpful to overcome the limitation of VaR only being able to measure the risk under the confidence level but not at the tail. A detailed 
introduction of the CVaR method can be found in the author's paper [22]. This paper constructs an objective function with the $\mathrm{CVaR}$ method. The objective function is designed as follows:

$$
F_{\beta}(E, \alpha)=\alpha+\frac{1}{1-\beta} \int_{y \in R^{m}}(L(E, y)-\alpha)^{+} p(y) d y
$$

where $\alpha$ indicates the threshold value of risk determination. $\beta$ indicates the objective function confidence of MEG operation. If Equation (37) achieves the minimum, it is the CVaR value. $\alpha$ indicates the VaR value. $L(E, y)=-R(E, y)$ indicates the loss function of MEG operation. $E^{T}=$ $\left[E_{M E G, t}(1), E_{M E G, t}(2), \cdots, E_{M E G, t}(T)\right]$ indicates the decision vector, and $y^{T}=\left[g_{W P P, t}, g_{P V, t}, L_{t}\right]$ indicates the multivariate random vector. $R(E, y)$ indicates the income function of MEG operation. According to Equation (35), the risk caused by the uncertainty factor in the objective function can be described.

In order to describe the uncertainty factors in the constraints, the conventional constraints need to be transformed into stochastic constraints. This paper used robust stochastic optimization theory to set deviations of predicted power of WPP and PV as $\delta_{W P P}$ and $\delta_{P V}$. Correspondingly, $g_{W P P, t}$ and $g_{P V, t}$ will fluctuate in intervals $\left[\left(1-\delta_{W P P, t}\right) \cdot g_{W P P, t}\left(1+\delta_{W P P, t}\right) \cdot g_{W P P, t}\right]$ and $\left[\left(1-\delta_{P V, t}\right) \cdot g_{P V, t},\left(1+\delta_{P V, t}\right) \cdot g_{P V, t}\right]$. In order to facilitate analysis, RE was introduced to represent WPP and PV, and $\delta_{R E, t}$ was introduced to represent $\delta_{W P P, t}$ and $\delta_{P V, t}$, then the uncertainty force was as follows:

$$
-\left[g_{R E, t}\left(1-\varphi_{R E}\right) \pm e_{R E, t} \cdot g_{R E, t}\right]=-\left[g_{W P P, t}\left(1-\varphi_{W P P}\right) \pm \delta_{W P P, t} \cdot g_{W P P, t}\right]-\left[g_{P V, t}\left(1-\varphi_{P V}\right) \pm \delta_{P V, t} \cdot g_{P V, t}\right]
$$

Further, since the WPP and PV uncertainty variables mainly appear in Equation (18), the system net load demand is set to be $M_{t}$ which can be calculated by Equation (37) as follows:

$$
M_{t}=-\left(L_{t}^{e}+g_{E S, t}^{\text {input }}+g_{P 2 G, t}^{\text {input }}+g_{P 2 H, t}^{\text {input }}+g_{P 2 C, t}^{\text {cinput }}+\Delta L_{t}^{p, P B}+\Delta L_{t}^{p, I B}\right)-g_{P S, t}^{\text {output }}-g_{P 2 G, t}^{\text {output }}-g_{C G T, t}
$$

Equation (17) can be rewritten according to Equations (38) and (39), as follows:

$$
-\left[g_{R E, t}\left(1-\varphi_{R E}\right) \pm e_{R E, t} \cdot g_{R E, t}\right] \leq M_{t}
$$

Referring to [23], for the flexibility of the stochastic model, auxiliary variables $\theta_{R E, t}(\theta \geq 0)$ and the robust coefficient $\Gamma_{R E}, \Gamma \in[0,1]$ were introduced to establish load supply and demand equilibrium constraints based on robust stochastic optimization theory, as follows:

$$
-\left(g_{R E, t}+\delta_{R E, t} g_{R E, t}\right) \leq-g_{R E, t}+\Gamma_{R E} \delta_{R E, t}\left|g_{R E, t}\right| \leq-g_{R E, t}+\delta_{R E, t} \theta_{R E, t} \leq M_{t}
$$

Finally, according to the objective function in Equation (35), combined with the constraints of Equations (40) and (19)-(31), a risk aversion optimization model with the CVAR method and robust stochastic optimization theory could be established. The specific model is as follows:

$$
\begin{array}{r}
\min F_{\beta}(G, \alpha)=\alpha+\frac{1}{N(1-\beta)} \sum_{k=1}^{N} z_{k} \\
\text { s.t. }\left\{\begin{array}{l}
E q \cdot(19)-E q \cdot(31) \\
E q .(37)-E q \cdot(39) \\
z_{k}=L(E, y)-\alpha \\
z_{k} \geq 0 \\
\text { other constriants }
\end{array}\right.
\end{array}
$$




\section{Example Analyses}

This paper chose the Xinxiang Active Distribution Network Demonstration Project in Jining, China as the example object to analyze the validity and applicability of the proposed model.

\subsection{Basic Data}

The Xinxiang Active Distribution Network Demonstration Project includes 1000 kW PV, 800 kW WPP, and $2000 \mathrm{~kW}$ CGT. The cost parameters of CGT operation were selected according to reference [21]. In order to facilitate the model solution, the CGT operation cost function was divided into two stages, and the slope coefficients were $0.55 ¥ / \mathrm{kW}$ and $0.15 ¥ / \mathrm{kW}$, respectively. In order to meet the demand of the multi-energy load of electricity, heat and cold, the demonstration project was equipped with $\mathrm{P} 2 \mathrm{H}$ $1500 \mathrm{~kW}$, P2C $1000 \mathrm{~kW}, \mathrm{H} 2 \mathrm{C} 1500 \mathrm{~kW}$, and P2G $150 \mathrm{~kW}$. The maximum energy storage and release power of PS and HS in this demonstration project was $200 \mathrm{~kW}$ and $300 \mathrm{~kW}$, the storage capacity was $1000 \mathrm{~kW} \mathrm{~h}$, the maximum energy storage and release power under CS was $300 \mathrm{~kW}$, and the energy storage capacity was $1000 \mathrm{~kW} / \mathrm{h}$. In addition, the demonstration project was equipped with a $500 \mathrm{~m}^{3}$ gas storage tank, and the maximum gas storage and supply power were both $150 \mathrm{~kW}$. The energy efficiency of the different energy equipment was $96 \%$. Considering that CGT operation can generate carbon emissions, this paper took $85 \%$ of the total carbon emissions from MEG operation as the MTEA, and chose a different energy load demand and real-time price of a typical load day as the basic data of the energy supply. Figure 3 is the electricity, heating, cooling, and gas load demand on a typical load day.
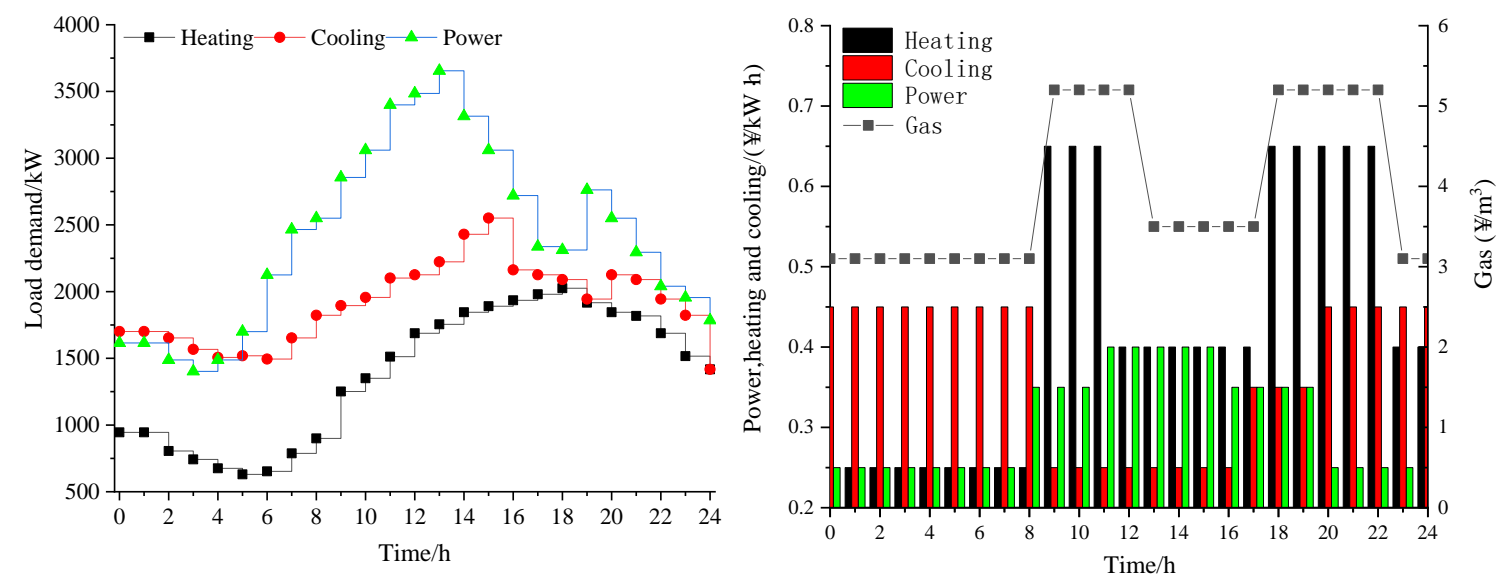

Figure 3. Electricity, heating, cooling, and gas load demand and real-time price on a typical load day.

Considering that EP, EC, ES and other energy equipment are dispatched and operated by the same entity, the WPP, PV, and CGT power generation price were $0.54 ¥ / \mathrm{kW} \cdot \mathrm{h}$ and $0.83 ¥ / \mathrm{kW} \cdot \mathrm{h}$. The CGT power supply price and heating supply price were $0.35 ¥ / \mathrm{kW} \cdot \mathrm{h}$ and $0.25 ¥ / \mathrm{kW} \cdot \mathrm{h}$. To promote the interconnection of WPP and PV, the EC electricity consumption price was set to $0.25 ¥ / \mathrm{kW} \cdot \mathrm{h}$, and the EC heating consumption price was set to $0.2 ¥ / \mathrm{kW} \cdot \mathrm{h}$ when converting energy. The electricity, heating and cooling prices provided by the demonstration project were executed at real-time prices of different energy markets, as shown in Figure 3. To analyze the influence of uncertainty, the WPP and PV parameters were set according to reference [10], and 10 typical WPP and PV output scenarios were generated by scenario simulation and the reduction method proposed in reference [19]. The most possible scenario was chosen as the input data, and the prediction deviation was set to $2 \%$. Figure 4 is the available output of WPP and PV on a typical day. 


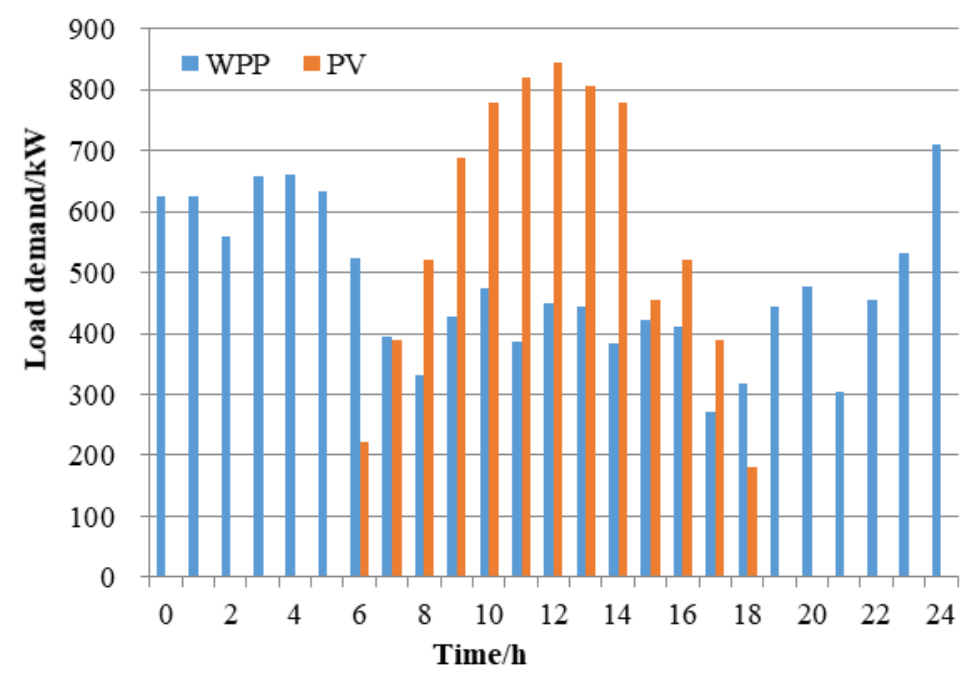

Figure 4. Available output of WPP and PV on a typical day. WPP: wind power plant; PV: photovoltaic power generation.

Thirdly, the model proposed in this paper includes 12 variables (four for production equipment, four for conversion equipment, and four for storage equipment), each of which includes 24 dimensions ( $24 \mathrm{~h}$ per scheduling period). To study the feasibility of CvaR and robust stochastic optimization theory in controlling WPP and PV uncertainty, confidence $\beta$ and the robust coefficient $\Gamma$ were both set to 0.8 , and three simulation scenarios were compared for analysis:

- Case 1: Basic scenario, scheduling of the MEG without uncertainty. This scenario does not take the uncertainty of WPP and PV into account. It analyzes the operation character of different compositions of the MEG and focuses on the complementary effects among them.

- Case 2: scenario with CVaR, dispatching of the MEG with the CVaR method. The scenario focuses on WPP and PV output uncertainty. CVaR is applied to change the objective function. By comparing and analyzing the scheduling result of MEG operation under different values of confidence $\beta$, the effectiveness of CVaR in dealing with the uncertainty of WPP and PV is verified.

- Case 3: Comprehensive scenario, dispatching of MEG with the CVaR-robust method. The scenario constructs stochastic constraints using robust stochastic optimization theory, and discusses the MEG dispatching optimal strategy with different robustness and prediction accuracy values, and analyzes the validity of the CVaR-robust method.

Finally, in order to analyze the optimal effect of the demand response of MEG operation, peak, flat, and valley periods of different load types of electricity, heating, and cooling were divided according to reference [21], and corresponding time-of-use (TOU) prices were set. Among them, the peak period price increased by $25 \%$, the valley period price decreased by $25 \%$, and the flat period price remained unchanged. The price elasticity of electricity, heating, and cooling was selected according to reference [21]. For the incentive demand response, the up-rotating reserve price and the down-rotating reserve price of the electricity, heating and cooling reserve markets were $0.85 ¥ / \mathrm{kW} \cdot \mathrm{h}$ and $0.25 ¥ / \mathrm{kW} \cdot \mathrm{h}$, $0.55 ¥ / \mathrm{kW} \cdot \mathrm{h}$ and $0.15 ¥ / \mathrm{kW} \cdot \mathrm{h}$, and $0.45 ¥ / \mathrm{kW} \cdot \mathrm{h}$ and $0.15 ¥ / \mathrm{kW} \cdot \mathrm{h}$, respectively. To avoid an excessive response of PBDR and IBDR, which would result in a "peak-to-valley upside down" phenomenon of the load curve, the total output of PBDR and IBDR should not exceed $10 \%$, and the output power should not exceed $100 \mathrm{~kW}$.

According to the above basic data, this paper used GAMs software to call CPLEX11.0 solver to solve the proposed model. The time for solving the above three simulation scenarios was less than $20 \mathrm{~s}$ by using the Lenovo IdeaPad 450 series notebook computers with 4 GB RAM and a Core T6500 processor. 


\subsection{Example Results}

\subsubsection{Scheduling Results of Case 1}

This scenario did not take the uncertainty effects of WPP and PV into account when analyzing the complementary effect among different energy components. The main optimization objectives of this scenario include maximizing the operational benefits and minimizing carbon emissions. Under the mode of following thermal load, the heating and cooling load are mainly satisfied by CGT, while the residual heating and cooling load are mainly satisfied by excess electricity through P2H and P2C. Table 1 shows the scheduling results of the micro energy grid of Case 1.

Table 1. Scheduling results of the micro energy grid of Case 1.

\begin{tabular}{|c|c|c|c|c|c|c|c|}
\hline & \multicolumn{3}{|c|}{ Energy Production/kW·h } & \multicolumn{4}{|c|}{ Energy Conversion $/ \mathbf{k W} \cdot \mathbf{h}$} \\
\hline & WPP & PV & $\begin{array}{l}\text { Conventional } \\
\text { gas turbine } \\
\text { (CGT) }\end{array}$ & $\begin{array}{l}\text { Power-to-heat } \\
\text { (P2H) }\end{array}$ & $\begin{array}{l}\text { Power-to-gas } \\
\text { (P2G) }\end{array}$ & $\begin{array}{l}\text { Power-to-cooling } \\
\text { (P2C) }\end{array}$ & $\begin{array}{c}\text { Heat-to-cooling } \\
\text { (H2C) }\end{array}$ \\
\hline Power & 10,731 & 7027 & 35,674 & -1967 & -2623 & $-14,649$ & - \\
\hline Heating & - & - & 57,600 & 1869 & - & - & $-10,724$ \\
\hline \multirow[t]{3}{*}{ Cooling } & - & - & - & - & - & 43,946 & 14,477 \\
\hline & \multicolumn{3}{|c|}{ Energy Storage/kW·h } & Gas storage & Revenue/\# & Carbon/ton & CVaR/羊 \\
\hline & $\begin{array}{l}\text { Power } \\
\text { storage } \\
\text { (PS) }\end{array}$ & $\begin{array}{c}\text { Heat } \\
\text { storage } \\
\text { (HS) }\end{array}$ & $\begin{array}{c}\text { Cooling } \\
\text { storage (CS) }\end{array}$ & tank (GST) & & & \\
\hline Power & \pm 2400 & - & - & 1129 & $14,882.59$ & 1.95 & - \\
\hline Heating & - & \pm 2400 & - & - & $21,474.53$ & 2.45 & - \\
\hline Cooling & - & - & \pm 3600 & - & $11,180.93$ & - & - \\
\hline
\end{tabular}

According to Table 1, if uncertainty risks are not considered, more WPP and PV will be scheduled to satisfy the electricity load, and the remaining power will be converted into heating and cooling through $\mathrm{P} 2 \mathrm{H}$ and $\mathrm{P} 2 \mathrm{C}$. Since the unit electricity energy can convert more cooling energy and obtain higher energy supply benefits, $14,649 \mathrm{~kW} \cdot \mathrm{h}$ electricity energy is converted into cooling energy. Since the cooling load is mainly converted by P2C and $\mathrm{H} 2 \mathrm{C}$, and there is no direct supply of cooling source, and the scheduled power of CS is higher than PS and HS at $\pm 3600 \mathrm{~kW}$. P2G can realize the cascade supply of electricity-gas-heating-cooling to obtain higher economic benefits by converting electricity energy into $\mathrm{CH}_{4}$, which will supply electricity and heating in CGT. Through the complementary operation of EP, EC, ES and other different energy components, the MEG can realize the coordinated supply of electricity, heating, and cooling, and the economic benefit of the MEG is 47,538.05¥. However, CGT and utility power grid (UPG) also generate 4.4 tons of carbon emissions. Figure 5 is the output distribution of the micro energy grid of Case 1.

According to Figure 5, the output distribution of micro energy grid at different times was analyzed. As far as electricity load is concerned, it was mainly satisfied by WPP, PV, and CGT, and PS stored electricity during valley times and released electricity during peak times. At the same time, since CGT operates in the mode of following thermal load, the MEG needed to buy electricity from UPG during peak times to satisfy the balance of power supply and demand. As far as heating load is concerned, CGT was the main source of heating, and the residual heating load is satisfied by P2H. HS stored heating during valley times and released heating during peak times. To satisfy the demand of cooling load, part of the heating entered H2C. As far as cooling load is concerned, P2C is the main source of cooling. This is because the unit electricity energy can be converted into more cooling energy. CS mainly stored cooling during valley times and released cooling during peak times. Through the coordinated operation of different energy components, the MEG was able to realize the optimal supply of electricity, heating, cooling, and other loads. 

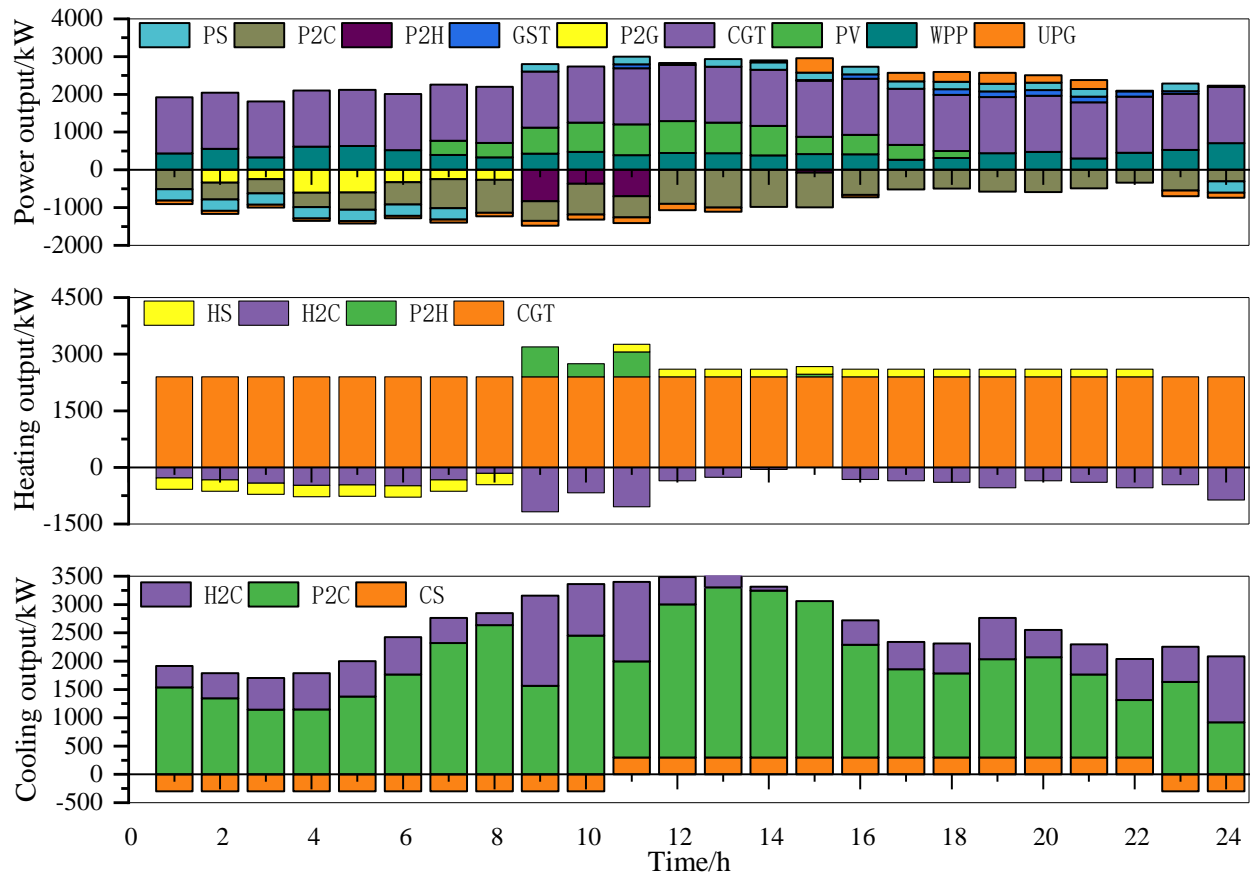

Figure 5. Output distribution of the micro energy grid of Case 1.

\subsubsection{Scheduling Results of Case 2}

This scenario analyzed the feasibility of the CVaR method when describing the uncertainty of WPP and PV. The CVaR method can transform the objective function using uncertain variables and construct the minimum risk objective function. Compared with Case 1, this scenario mainly considered three objective functions, which are maximizing economic benefits, minimizing operational risks, and minimizing carbon emissions, in order to discuss the MEG's optimal scheduling scheme. Table 2 shows the dispatching results of the micro energy grid of Case 2.

Table 2. Dispatching results of the micro energy grid of Case 2.

\begin{tabular}{|c|c|c|c|c|c|c|c|}
\hline & \multicolumn{3}{|c|}{ Energy Production/kW·h } & \multicolumn{3}{|c|}{ Energy Storage/kW·h } & \multirow{2}{*}{ GST } \\
\hline & WPP & PV & CGT & PS & HS & $\mathrm{CS}$ & \\
\hline Power & 10,166 & 6657 & 35,674 & \pm 2400 & - & - & 814 \\
\hline Heating & - & - & 57,600 & - & \pm 2400 & - & - \\
\hline \multirow[t]{3}{*}{ Cooling } & - & - & - & - & - & \pm 3600 & - \\
\hline & \multicolumn{4}{|c|}{ Energy Conversion/kW·h } & Doranut & & CVGD \\
\hline & $\mathbf{P} 2 \mathrm{H}$ & P2G & P2C & $\mathrm{H} 2 \mathrm{C}$ & Kevenue/f & Carbon/ton & CVak/¥ \\
\hline Power & -2231 & -1223 & $-14,536$ & - & $14,268.502$ & 2.25 & 9702.581 \\
\hline Heating & 2091 & - & - & $-10,947$ & $21,555.33$ & 2.68 & 9268.792 \\
\hline Cooling & - & - & 43,607 & 14,778 & $11,324.708$ & - & 3284.165 \\
\hline
\end{tabular}

According to Table 2, the MEG scheduling results, considering uncertainty, were analyzed. When considering uncertainty, the MEG will reduce dispatching of WPP and PV and increase electricity bought from UPG to reduce uncertainty risk. Compared with Case 1, the WPP and PV grid-connected power were reduced by $585 \mathrm{~kW} \cdot \mathrm{h}$ and $370 \mathrm{~kW} \cdot \mathrm{h}$, respectively, and the power provided by UPG increased by $848 \mathrm{~kW} \cdot \mathrm{h}$, resulting in an increase of 0.53 tons of carbon emissions. When the CGT operates in the mode of following thermal load, the remaining power of WPP and PV is converted into heating to obtain more economic benefits. Overall, if taking the uncertainty of WPP and PV into account, MEG tends to buy electricity from UPG to avoid risk, and the remaining electricity is 
converted into heating to realize the coordinated supply of electricity, heating, and cooling, which brings about a lower risk value to MEG operation than electricity energy. Further, this case analyzed the MEG output scheme considering uncertainty. Figure 6 is the output distribution of the micro energy grid of Case 2.
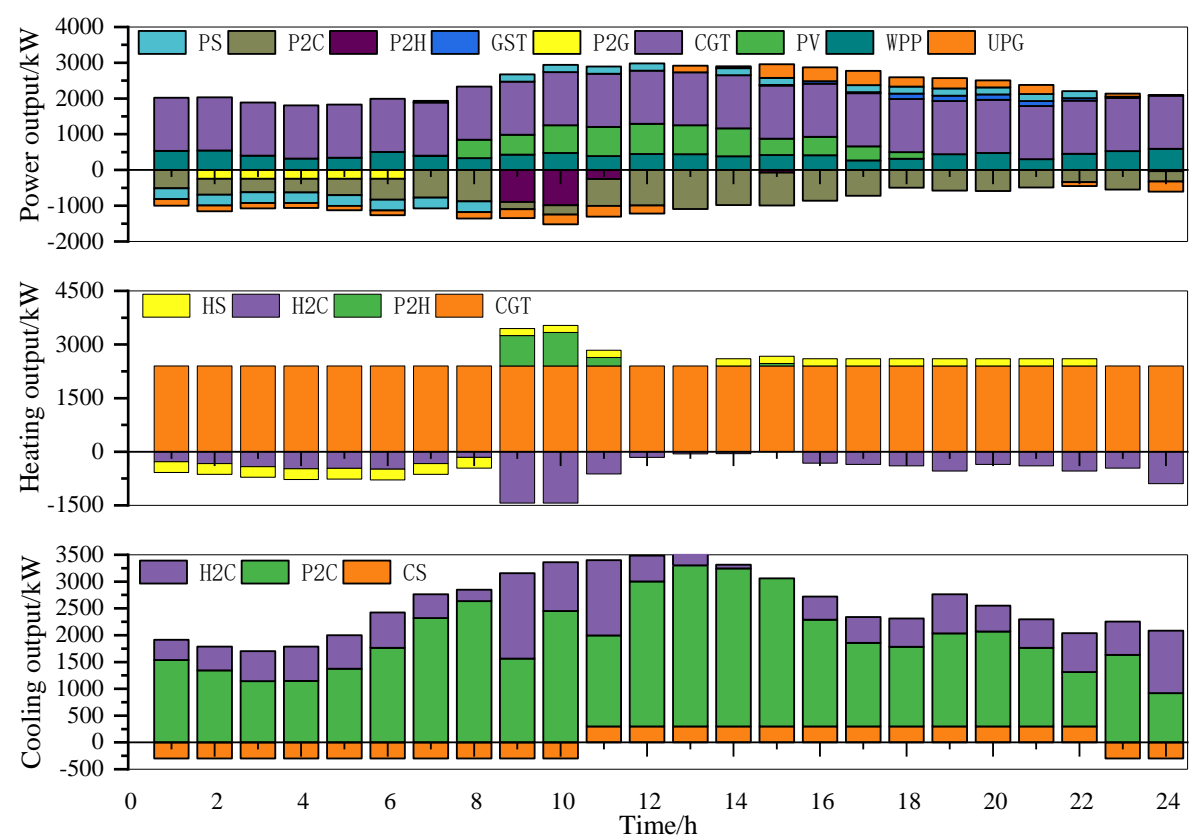

Figure 6. Output distribution of the micro energy grid of Case 2.

According to Figure 6, the MEG output distribution considering uncertainty was analyzed. When considering the uncertainty, the grid-connected power of WPP and PV decreased. At the same time, less power entered into $\mathrm{P} 2 \mathrm{G}$, which led to a decrease in GST power generation output, but the power supplied by UPG during peak times was significantly improved. From the perspective of different loads, since the surplus electricity is converted into heating, the heating energy provided by $\mathrm{P} 2 \mathrm{H}$ increases, but the cooling load supply structure remains basically unchanged. This shows that when uncertainty is considered, the power output structure will change greatly, while the heating source and cooling source output structure will change relatively little. Further, the MEG scheduling results under different confidence levels were analyzed.

According to Table 3, it can be seen that as the increase of the confidence in grid-connected power of WPP and PV decreases, the power supply of UPG increases gradually. Correspondingly, the objective function values increase. This shows that benefits and risks are concomitant. If the decision makers expect to obtain high environmental and economic benefits, they have to bear more operational risks. On the contrary, if decision makers pursue the safe and steady operation of the MEG, they have to sacrifice some of the potential economic benefits. In general, CVaR can describe uncertainty, and provide a basis for decision makers who have different risk attitudes by setting a confidence level to establish the optimal scheduling strategy of the MEG. 
Table 3. Scheduling results of the micro energy grid under different confidence levels.

\begin{tabular}{|c|c|c|c|c|c|c|c|c|}
\hline & \multirow{2}{*}{ WPP } & \multirow{2}{*}{ PV } & \multicolumn{2}{|c|}{ CGT } & \multirow{2}{*}{ UPG } & \multirow{2}{*}{ Revenue/¥ } & \multirow{2}{*}{ Carbon/ton } & \multirow{2}{*}{ CVaR/¥ } \\
\hline & & & Power & Heating & & & & \\
\hline 0 & $10,731.2$ & 7027.15 & $35,673.6$ & 57,600 & \pm 1647.83 & $47,538.051$ & 4.4 & 0 \\
\hline 0.5 & $10,668.26$ & 6998.85 & $35,673.6$ & 57,600 & \pm 1745.25 & $47,493.781$ & 4.46 & 6152.16 \\
\hline 0.6 & $10,542.38$ & 6942.25 & $35,673.6$ & 57,600 & \pm 1945.24 & $47,405.24$ & 4.58 & $18,456.48$ \\
\hline 0.7 & $10,354.39$ & 6799.776 & $35,673.6$ & 57,600 & \pm 2207.525 & $47,276.89$ & 4.755 & $20,356.01$ \\
\hline 0.8 & 10,166 & 6657 & $35,673.6$ & 57,600 & \pm 2469.81 & $47,148.54$ & 4.93 & $22,255.54$ \\
\hline 0.9 & $10,026.13$ & 6377.767 & $35,673.6$ & 57,600 & \pm 2685.12 & $46,391.147$ & 5.26 & $23,729.51$ \\
\hline 1.0 & 9956 & 6238 & $35,673.6$ & 57,600 & \pm 2845.85 & $46,012.45$ & 5.43 & $24,466.5$ \\
\hline
\end{tabular}

\subsubsection{Scheduling Results of Case 3}

This scenario analyzed the validity of robust stochastic optimization theory in controlling uncertain variables of constraints. Compared with scenario 2, this scenario introduced both the CVaR method and robust stochastic optimization theory, which further strengthened the constraints on uncertainty. In order to avoid WPP and PV uncertainty risks, the MEG reduced scheduling of WPP and PV. The output of WPP and PV decreased to $9602 \mathrm{~kW} \cdot \mathrm{h}$ and $6287 \mathrm{~kW} \cdot \mathrm{h}$, respectively. Correspondingly, the MEG operating income also reduced. Table 4 shows the dispatching results of the micro energy grid of Case 3.

Table 4. Scheduling results of micro energy grid of Case 3.

\begin{tabular}{|c|c|c|c|c|c|c|c|}
\hline & \multicolumn{3}{|c|}{ Energy Production/kW·h } & \multicolumn{3}{|c|}{ Energy Storage/kW·h } & \multirow{2}{*}{ GST } \\
\hline & WPP & PV & CGT & PS & HS & CS & \\
\hline Power & 9602 & 6287 & 35,674 & \pm 2400 & - & - & 153 \\
\hline Heating & - & - & 57,600 & - & \pm 2400 & - & - \\
\hline \multirow[t]{3}{*}{ Cooling } & - & - & - & - & - & \pm 3300 & - \\
\hline & \multicolumn{4}{|c|}{ Energy Conversion/kW·h } & & & \\
\hline & $\mathbf{P} 2 \mathrm{H}$ & P2G & P2C & $\mathrm{H} 2 \mathrm{C}$ & 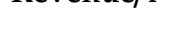 & - & \\
\hline Power & -73 & -230 & $-16,091$ & - & $13,398.987$ & 2.47 & 8709.342 \\
\hline Heating & 70 & - & - & -7586 & $21,464.787$ & 2.83 & 9229.858 \\
\hline Cooling & - & - & 48,273 & 10,241 & $11,581.694$ & - & 4053.593 \\
\hline
\end{tabular}

Furthermore, the output distribution of the micro energy grid at different times was analyzed. Compared with Figure 5, when considering robust stochastic optimization theory, the WPP and PV uncertain variables in the constraints could be described. The corresponding output power of WPP and PV decreased, especially during peak times. The MEG will buy more power from UPG, thus reducing operational risks. Because part of WPP and PV are converted into heating, which creates uncertainty in the heating load supply, the MEG will buy some energy from UHG and UCG to realize a reliable supply of heating and cooling, to reduce the risk to the heating and cooling supply. This means that the introduction of the CVaR method and robust stochastic optimization theory can control the energy supply risk of electricity, heating and cooling loads simultaneously, and take into account both operational benefits and risks, to achieve the optimal safe and steady operation of the MEG. Figure 7 is the output distribution of the micro energy grid of Case 3. 

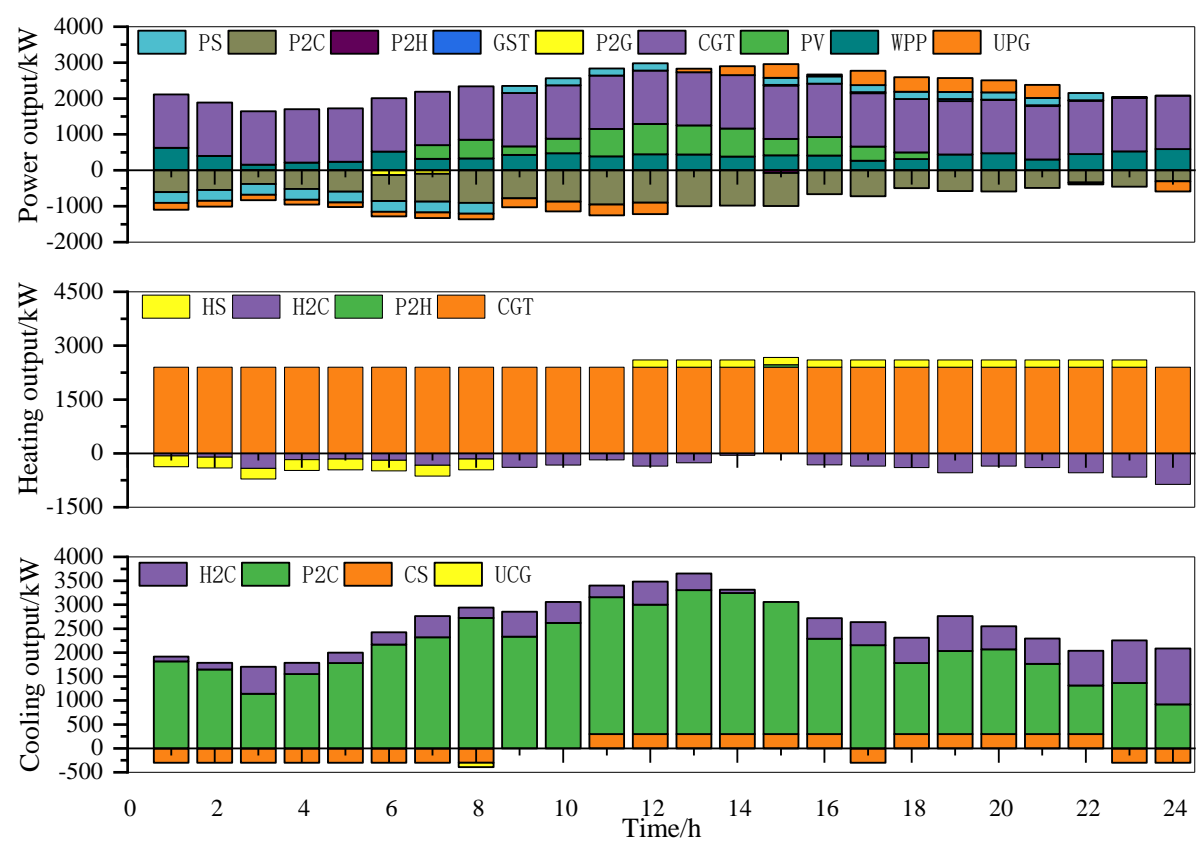

Figure 7. Output distribution of the micro energy grid of Case 3.

In addition, to study the applicable space of the risk aversion model, a sensitivity analysis of the robustness coefficient and confidence was carried out. It can be seen that when $0.7<\Gamma \leq 0.95$, the increase of $\beta$ will result in a larger improvement of $C V a R$, which means that the MEG operation scheme will change when considering WPP and PV uncertainty. When $\Gamma \leq 0.7$, the increase of $\beta$ will result in a lower increase of CVaR. The decision makers will pay attention to the operation benefits and risks of the MEG at the same time, so the operation of the MEG is relatively steady, but the overall $\mathrm{CVaR}$ value will increase with the increase of $\Gamma$. When $\Gamma \geq 0.95$, the increase of $\beta$ will bring a great increase of $\mathrm{CVaR}$. In this case, the decision makers are extremely risk averse. A smaller uncertainty will bring greater operational risk. Figure 8 is the analysis result of the MEG operational risk under different robustness coefficients and confidence levels.

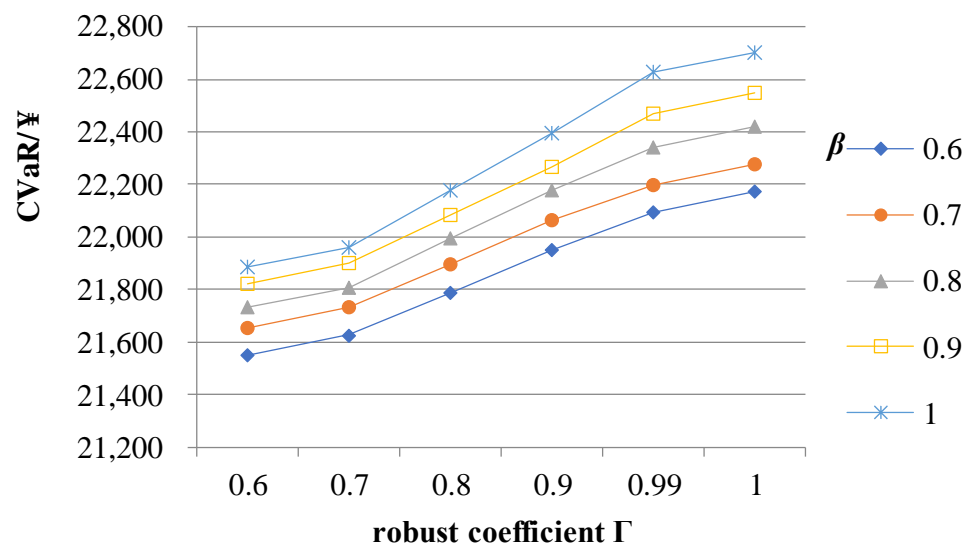

Figure 8. The analysis result of the MEG operational risk under different robustness coefficients and confidence levels.

In general, the CVaR method and robust optimization theory can better describe the uncertain risk of MEG operation. To realize the optimal operation of the MEG, decision makers should set reasonable confidence and robustness coefficients, considering the operational risks and benefits of the MEG at the same time. 


\subsection{Results Analysis}

According to the above three scenarios, the impact of demand response and MTEA on MEG operation is further analyzed to establish external key factors of MEG operation.

(1) DR optimization effect analysis

DR includes two response modes: PBDR and IBDR. PBDR indirectly leads terminal users to use energy reasonably by implementing a differentiated time-of-use price. IBDR directly controls the terminal users' load by signing a pre-agreement with them. Figure 9 is the load curve of power, heating and cooling before and after PBDR.

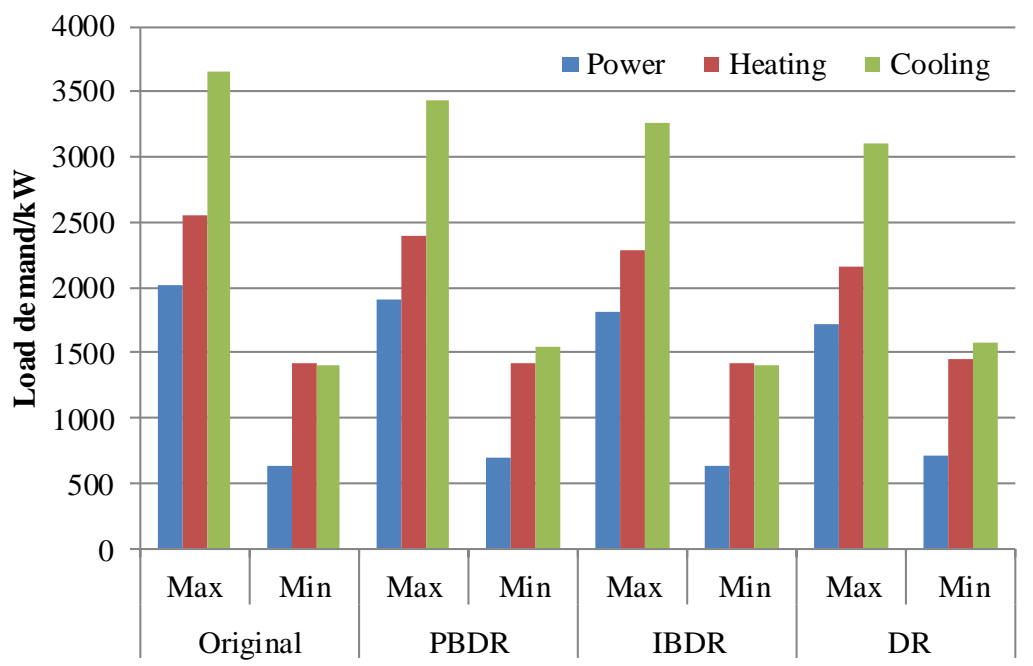

Figure 9. Load curve of power, heating and cooling after demand response (DR). PBDR: price-based demand response; IBDR: incentive-based demand response.

Compared with original load curve, the maximum load of peak time after PBDR decreases, and the minimum load of valley time increases. The maximum load reduction effect after IBDR is stronger than that of PBDR, but the valley load enhancement effect is weaker than that of PBDR. At the same time, after the application of PBDR and IBDR, the peak load decreases more, the valley load increases more, and the load curve becomes smoother. Table 5 shows the dispatching results of the micro energy grid before and after PBDR.

Table 5. Dispatching results of the micro energy grid before and after PBDR.

\begin{tabular}{|c|c|c|c|c|c|c|c|}
\hline \multirow{2}{*}{ PBDR } & \multirow{2}{*}{ WPP } & \multirow{2}{*}{ PV } & \multicolumn{2}{|c|}{ CGT } & \multicolumn{3}{|c|}{ Energy Storage/kW·h } \\
\hline & & & Power & Heating & PS & HS & CS \\
\hline Before & 9602 & 6287 & 35,674 & 57,600 & \pm 2400 & \pm 1800 & \pm 3000 \\
\hline After & 10,167 & 6657 & 35,674 & 57,600 & \pm 1800 & \pm 2400 & \pm 3600 \\
\hline \multirow{2}{*}{ PBDR } & \multirow{2}{*}{ GST } & & IBDR & & \multirow{2}{*}{ Revenue/ $¥$} & \multirow{2}{*}{ Carbon/ton } & \multirow{2}{*}{$\mathrm{CVaR} / \#$} \\
\hline & & Power & Heating & Cooling & & & \\
\hline Before & 153 & - & - & - & 46,445 & 5.30 & 21,993 \\
\hline After & 86 & \pm 1200 & \pm 1000 & \pm 1200 & 50,935 & 4.60 & 22,189 \\
\hline
\end{tabular}

According to Table 5, if PBDR is considered, the WPP and PV grid-connected power are increased by $565 \mathrm{~kW} \cdot \mathrm{h}$ and $370 \mathrm{~kW} \cdot \mathrm{h}$, respectively. As the load curve becomes smoother, the output of PS, HS, and CS decreases, indicating that the peak load regulation demand of the MEG for WPP and PV decreases. Similarly, after PBDR, the load in the valley period increases and the convertible power of P2G decreases. From the operational objective function, the economic benefits, carbon emissions and 
CVaR values of MEG operation after PBDR are all optimized. Further, the output distribution of MEG at different times after PBDR was analyzed. Figure 10 is the output distribution of the micro energy grid after PBDR.
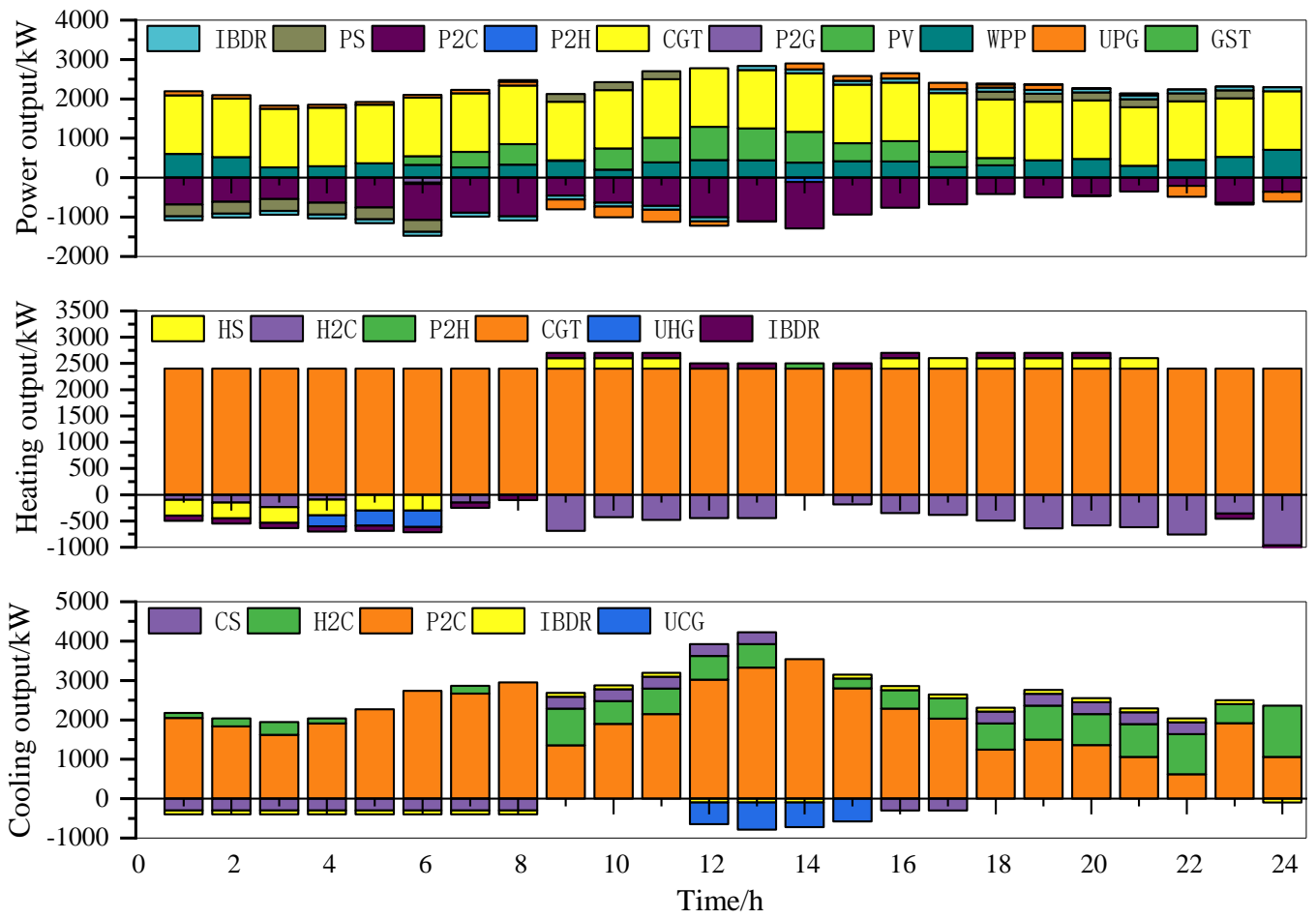

Figure 10. Output distribution of the micro energy grid after PBDR.

According to Figure 10, the output distribution of the MEG at different times was analyzed. Due to PBDR the load curve became smoother, and the WPP grid-connected power increased in the valley period. The PV grid-connected power increased in the peak period because IBDR can provide a peak-shaving service. In terms of power load, the power supply structure was cleaner and lower in carbon due to the increased power generation of WPP and PV. In terms of heating and cooling load, the smoother load curves reduced peak-shaving demand, make full use of IBDR, which can provide a peak-shaving service, which optimizes the meeting efficiency of the heating load and cooling load. In general, PBDR can optimize the output structure of the MEG and improve the operational efficiency of the MEG.

(2) MTEA sensitivity analysis

For the MEG, the main carbon emission sources include CGT and UPG. Therefore, the setting of MTEA will directly affect the power supply of CGT and UPG to the MEG. Therefore, this section outlines the sensitivity analysis we carried out on MTEA to construct the optimal dispatching strategies with different MTEAs. Table 6 shows the dispatching results of the micro energy grid with different META.

Table 6. Scheduling results of the micro energy grid under different META.

\begin{tabular}{|c|c|c|c|c|c|c|c|c|c|c|c|}
\hline \multirow{2}{*}{ META } & \multirow{2}{*}{ WPP } & \multirow{2}{*}{ PV } & \multicolumn{3}{|c|}{ IBDR } & \multicolumn{3}{|c|}{ ES } & \multirow{2}{*}{$\begin{array}{c}\text { Carbon } \\
\text { Emission/ton }\end{array}$} & \multirow{2}{*}{ Revenue/103¥ } & \multirow{2}{*}{ CVaR/103 } \\
\hline & & & Power & Heating & Cooling & Power & Heating & Cooling & & & \\
\hline $60 \%$ & 11,258 & 7045 & \pm 1600 & \pm 1300 & \pm 1500 & \pm 2400 & \pm 3000 & \pm 3900 & $55,688.93$ & 3.45 & 27,854 \\
\hline $70 \%$ & 11,085 & 6842 & \pm 1400 & \pm 1200 & \pm 1300 & \pm 1800 & \pm 3000 & \pm 3900 & $53,554.51$ & 4.03 & $25,358.86$ \\
\hline $80 \%$ & 10,167 & 6657 & \pm 1200 & \pm 1000 & \pm 1200 & \pm 1800 & \pm 2400 & \pm 3600 & 50,935 & 4.60 & 22,189 \\
\hline $90 \%$ & 9650 & 6245 & \pm 1100 & \pm 800 & \pm 900 & \pm 1800 & \pm 1800 & \pm 3000 & $47,539.33$ & 5.18 & $19,723.56$ \\
\hline $100 \%$ & 9325 & 6018 & \pm 900 & \pm 700 & \pm 900 & \pm 1200 & \pm 1800 & \pm 3000 & $44,822.8$ & 5.75 & $17,751.2$ \\
\hline
\end{tabular}


According to Table 6, with the increase of META, the power generation of WPP and PV gradually decreased. This is because the MEG is more inclined to buy power from UPG to avoid uncertain risks. It also reduces ES and IBDR output, meaning that the demand of the MEG for reserve services is reduced. When META is small, the carbon emissions of CGT and UPG power generation will reduce their power generation advantages, while more WPP and PV are scheduled to satisfy the load demand. Generally speaking, a reasonable META needs to be set to enhance WPP and PV grid-connected space and realize the optimal operation of the MEG as a whole.

\section{Conclusions}

In order to improve the sustainable development of distributed energy such as wind and solar, this paper emphasized optimization of the operation of the micro energy grid aggregated by multiple distributed energy sources. Because of the strong uncertainty of WPP and PV, the CVaR method and robust stochastic optimization theory were applied to describe the uncertainty of the objective function and constraints, and a risk aversion dispatching model of the micro energy grid considering the demand response and maximum total emission allowance was constructed. Finally, this paper selected the Xinxiang Active Distribution Network Demonstration Project in Jining, China as an example. The following conclusions were reached:

(1) The micro energy grid can make the most use of the complementary characters of different energy, such as WPP, PV, and CGT, and can make use of a variety of EC equipment (P2H, P2C, H2C, P2G) and ES equipment (PS, HS, CS, GS) to achieve optimal satisfaction with various loads types, such as electricity, heating, cooling and gas. On the one hand, clean energy has both environmental and economic characteristics, which can improve the economic and environmental benefits of MEG operation. On the other hand, the cooperative operation of various EC and ES can effectively handle the strong uncertainty.

(2) The proposed risk aversion dispatching optimization model with the CVaR method and robust stochastic optimization theory can describe the impact of uncertain variables in objective function and constraints, and provide a basis for decision makers who have different attitudes. When $\Gamma \leq 0.7$, $\beta$ increases and results in a lower increase of $C V a R$, and decision makers are operating in risk-free conditions. When $0.7<\Gamma \leq 0.95, \beta$ increases and results in a larger increase, the decision makers are risk-averse. When $\Gamma \geq 0.95, \beta$ increases and results in a lower increase, and the decision maker becomes extremely risk averse. Thus, it is possible to formulate the optimal scheduling strategy for decision makers who have different attitudes by setting reasonable confidence and robustness coefficients.

(3) DR can smooth the energy load curve of electricity, heating, cooling, and gas. MTEA can enhance the market competitiveness of the clean energy market, thus promoting grid-connected power of clean energy, such as WPP and PV, and optimizing the multi-energy supply structure of the MEG. On the one hand, PBDR has a better "valley filling" effect, and IBDR has a better "peak cutting" effect. The synergistic operation of the two can maximize the "peak cutting and valley filling" effect. On the other hand, MTEA determines the supply space of CGT and UPG. When MTEA is low, the MEG gives priority to WPP and PV to satisfy the load demand, which will meet the maximum carbon emission constraint.

Author Contributions: Conceptualization, P.L.; methodology, W.F.; software, L.J.; resources, N.L. and F.Z.; data curation, F.Z.; writing —original draft preparation, X.F.; writing—review and editing, X.F. and H.L.; visualization, L.J.

Funding: This research was funded and supported by the Project funded by China Postdoctoral Science Foundation (2019M650024), the National Nature Science Foundation of China (Grant Nos. 71904049, 71874053, 71573084), the Beijing Social Science Fund (18GLC058) and the 2018 Key Projects of Philosophy and Social Science Research, Ministry of Education, China (18JZD032).

Conflicts of Interest: The authors declare no conflict of interest. It should be noted that the whole work was accomplished by the authors collaboratively. All authors read and approved the final manuscript. 


\section{Nomenclature}

Abbreviation

MEG

MTEA

WPP

PV

CGT

P2G

$\mathrm{P} 2 \mathrm{C}$

$\mathrm{P} 2 \mathrm{H}$

H2C

GS

PS

HS

CS

DR

PBDR

IBDR

EP

EC

ES

FET

FTL

Set

$t, s$

k

j

Parameter

$g_{R}$

$v_{\text {in }}$

$v_{R}$

$v_{\text {out }}$

$\eta_{P V}$

$S_{P V}$

$H_{n g}$

$\eta_{C G T, t}$

$\theta_{t}$

$v_{t}$

$L_{t}^{\text {output }}$

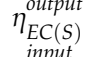

$\eta_{E C(S)}^{\text {input }}$

$\eta_{t}^{\text {loss }}$

Variables

$g_{C G T, t}$

$Q_{C G T, t}$

$V_{C G T, t}$

$Q_{P 2 C, t}$

$Q_{P 2 H, t}$

$Q_{\mathrm{H} 2 \mathrm{C}, \mathrm{t}}$

$g_{P 2 C, t}$

$g_{P 2 H, t}$

$g_{\mathrm{H} 2 \mathrm{C}, t}$

$S_{E S, t}$

$E S_{t}^{\text {input }}$

$E S_{t}^{\text {output }}$

$\Delta P_{t}$

$\Delta L_{s}$

$\Delta L_{t}^{k, I B}$

$R_{E P, t}$

$R_{E C, t}$ micro energy grid

maximum total carbon emission allowance

wind power plant

photovoltaic power generation

conventional gas turbine

power-to-gas

power to cooling

power to heating

heating to cooling

gas storage tank

power storage battery

heat storage tank

cold storage tank

demand response

price-based demand response

incentive-based demand response

energy production

energy conversion

energy storage

following electric load

following thermal load

index for time

index for energy type

index for step

rated power of WPP

cut-in speed

rated speed

cut-out speed

conversion productivity

receiving light of $\mathrm{PV}$

natural gas calorific value

operation efficiency of CGT at time $t$

radiation intensity at time $t$

real-time speed at time $t$

initial load before PBDR. at time $t$

energy use efficiency of EC and ES

energy supply efficiency of EC and ES

loss rate of ES at time $t$

power supply of CGT at time $t$

heating supply of CGT at time $t$

gas consumption at time $t$

cooling power produced by P2C at time $t$

heating power from $\mathrm{P} 2 \mathrm{H}$ at time $t$

cooling power from $\mathrm{H} 2 \mathrm{C}$ at time $t$

electricity consumption of $\mathrm{P} 2 \mathrm{C}$ at time $t$

electricity consumption of $\mathrm{P} 2 \mathrm{H}$ at time $t$

heating consumption of $\mathrm{H} 2 \mathrm{C}$ at time $t$

energy storage of ES at time $t$

Input power of ES at time $t$

output power of ES at time $t$

price variable after PBDR at time $s$

load variable after PBDR at time $s$

output power of energy $k$ provided by IBDR at time $t$

operation revenue of EP at time $t$

operation revenue of $\mathrm{EC}$ at time $t$ 


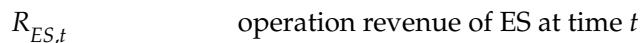

$R_{D R, t} \quad$ operation revenue of DR at time $t$

$R_{\text {Carbon,t }} \quad$ carbon trading revenue at time $t$

$C_{C G T, t}^{\text {fuel }}$

$C_{C G T, t}^{s d}$

fuel consumption cost of CGT at time $t$

$u_{C G T, t}$

start-stop cost of CGT at time $t$

$g_{C G T, t}$

$Q_{C G T, t}$

start-up and shut-down state variable at time $t$

power output of CGT at time $t$

heating output of CGT at time $t$

$\mu_{C G T, t}^{u}$

start-up state variable of CGT at time $t$

$\Delta g_{C G T}^{-}$

downhill power limits of CGT

$\Delta g_{C G T}^{+}$

uphill power limits of CGT

$u_{\text {OUtput }}$

operating status of the CGT

state variables of EC outputting energy at time $t$

$\Delta L_{t}^{c}$

load forecast deviation at time $t$

$M_{t}$

system net load demand

$D_{i}^{k, j, \max } D_{i}^{k, j, \max }$

$D_{i}^{k, j, \min }$

maximum output of DRP $i$ in step $j$ providing energy $k$

$\Delta L_{i, j}^{k, j}$

minimum response output of DRP $i$ in step $j$ providing energy $k$

$D_{i, t}^{k, j}$

actual load reduction value of energy $k$ that DRP $i$ provides in $j$ step at time $t$

$\theta_{h}^{e, t}$

available load reduction value of energy $k$ that DRP $i$ can provides in step $j$ at time $t$

electric-thermal conversion coefficient of CGT

$a, b, c$

$P^{\text {before }}$

power supply cost coefficient of CGT

$P_{t}^{a f t e r}$

energy price before PBDR at time $t$

$a_{\mathrm{CGT}}, b_{\mathrm{CGT}}, c_{\mathrm{CGT}}$

energy price after PBDR at time $t$

$c_{\min }, c_{\max }$

$Q_{C G T}^{\max }$

$Q_{C G T}^{\min }$

$g_{C G T}^{\min }, g_{C G T}^{\max }$

$V_{P 2 G, t^{\prime}}^{\min } V_{P 2 G, t}^{\max } \quad$ minimum and maximum gas production power of $\mathrm{P} 2 \mathrm{G}$

carbon emission coefficient of the CGT

value of $c$ with the minimum and maximum output power

maximum heating power of CGT

heating supply power of the turbine when electricity power supply of CGT is minimum

maximum and minimum power generation of CGT under pure condensation

,$Q_{E C, t}^{\text {output,max }}$ upper and lower limits of EC energy supply

$Q_{E C, t}^{\text {input,min }}$,

e $Q_{E C, t, \text { in }}^{\text {in }}$

$S_{E S, t}^{\min ,} S_{E S, t}^{\max }$

$g_{E S, t}$

output, max

$g_{E S, t}$

$Q_{E S, t}^{\text {int } \text { min }}$,

$Q^{\text {input, max }}$

$Q_{E S, t}^{\text {input }}$

$r_{e}, r_{c}$

$r_{W P P}^{u p}, r_{P V}^{u p}$

$r_{W P P}^{d n}, r_{P V}^{d n}$

$g_{M E G, t}^{p, \max }, g_{M E G, t}^{p, \min }$

$\mathrm{E} \varphi, \vartheta$

$\omega, \psi$

upper and lower limits of EC energy consumption

minimum and maximum energy storage of ES at time $t$

minimum and maximum of ES energy supply at time $t$

minimum and maximum limits of ES energy consumption at time $t$

up-rotating reserve coefficients of electricity and cooling load

up-rotating reserve coefficients of WPP and PV

down-rotating reserve coefficients of WPP and PV

maximum and minimum power supply at time $t$

shape and scale parameter

shape parameters of the Beta distribution

$\eta_{h r}$

heat recovery efficiency

$\varphi_{P 2 C}$

$\eta_{\text {loss }}$

energy conversion efficiency of P2C,

capacity loss rate

$\varphi_{P 2 H}$

$\varphi_{\mathrm{H} 2 \mathrm{C}}$

$\eta_{E S}^{\text {input }}$

$\eta_{\text {Output }}$

$E_{\text {st }}$

energy conversion efficiency of $\mathrm{P} 2 \mathrm{H}$

energy conversion efficiency of $\mathrm{H} 2 \mathrm{C}$

energy storage efficiency

energy release efficiency

energy demand price elasticity matrix

$g_{P V, t}^{*}$

maximum output power of PV at time $t$

$g_{W P P, t}^{*}$

available power of WPP at time $t$

$\mu_{\text {CGT, }}^{d}$

$C_{C G T, t}^{u}$

shut-down state variable of CGT at time $s$

start-up cost at time $t$

$C_{C G T, s+1}^{d}$

hut-down cost of CGT at time $s+1$ 


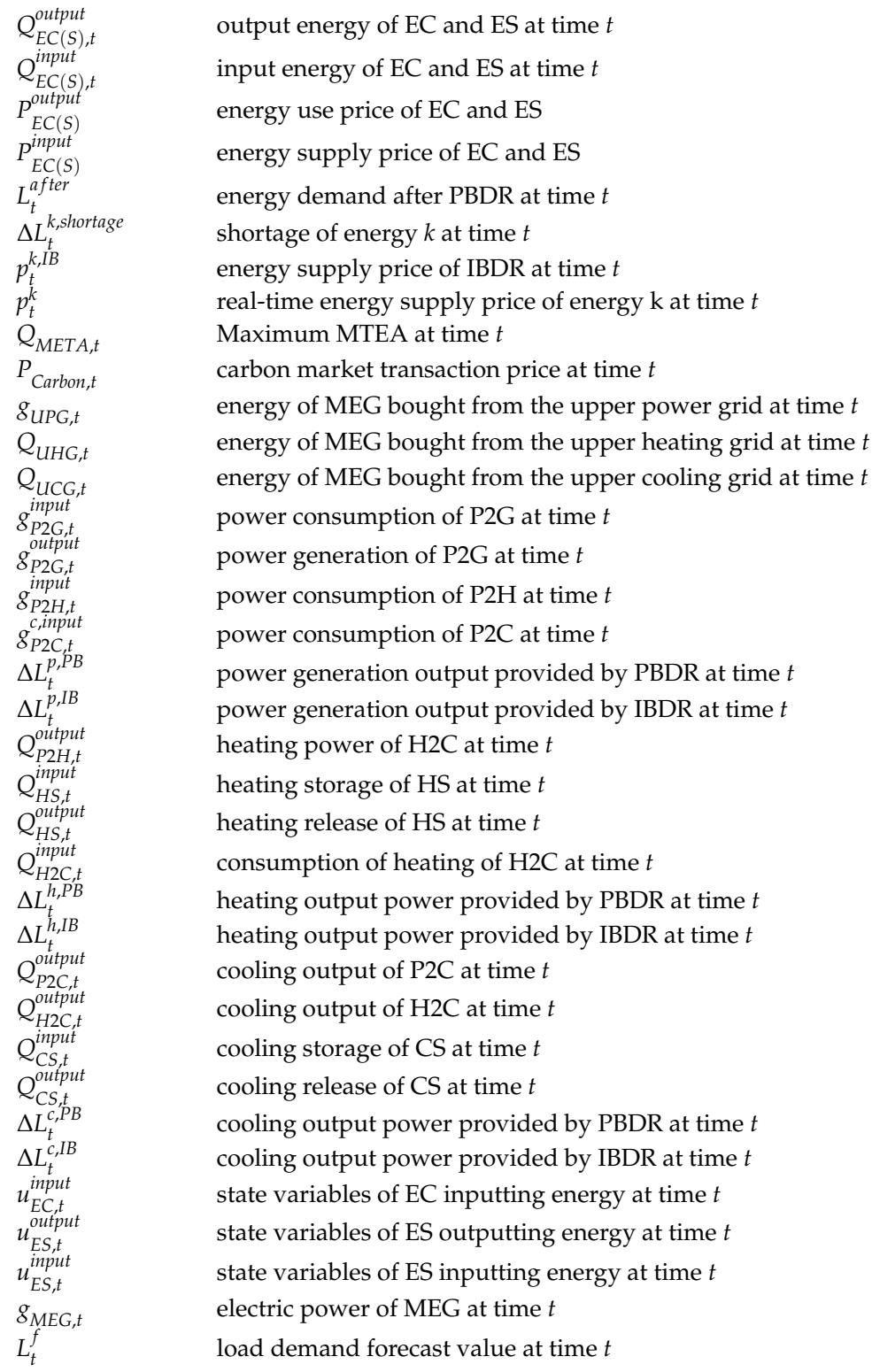

\section{References}

1. Rifkin, J. The Third Industrial Revolution: How Lateral Power is Transforming Energy, the Economy, and the World; St. Martin's Press: New York, NY, USA, 2011.

2. Guidance on Promoting the Development of "Internet +" Smart Energy. Available online: https://kns.cnki.net/K CMS/detail/detail.aspx?dbcode=CJFQ\&dbname=CJFDLAST2016\&filename=CSYQ201604001\&v=MTgxNTZy V00xRnJDVVJMT2VaZVpzRnluaFZidlBKajdTZjdHNEg5Zk1xNDlGWliSOGVYMUx1eFlTNORoMVQzcVQ=) (accessed on 4 November 2019).

3. Liu, Y.B.; Zuo, K.Y.; Liu, X.W. Dynamic pricing for decentralized energy trading in micro-grids. Appl. Energy 2018, 228, 689-699. [CrossRef]

4. Rossi, I.; Banta, L.; Cuneo, A.; Ferrari, M.L.; Traverso, A.N.; Traverso, A. Real-time management solutions for a smart polygeneration microgrid. Energy Convers. Manag. 2016, 112, 11-20. [CrossRef]

5. Dong, W.L.; Wang, Q.; Yang, L. A coordinated dispatching model for distribution utility and virtual power plants with wing/photovoltaic/hydro generators. Autom. Electr. Power Syst. 2015, 39, 75-82.

6. Yu, S.; Wei, Z.H.; Sun, G.Q. A bidding model for a virtual power plant considering uncertainties. Autom. Electr. Power Syst. 2014, 38, 44-49. 
7. Liu, X.Y. Research on Performance of Combined Heating System of Solar Energy and Electric Boiler, North China Electric Power University. 2017. Available online: https://kns.cnki.net/KCMS/detail/detail.aspx?d bcode $=$ CMFD\&dbname $=$ CMFD201801\&filename=1017222760.nh\&v=MTE4NzJGeW5oVnIzQ1ZGMjZH Ykc2SE5iS3I1RWJQSVI4ZVgxTHV4WVM3RGgxVDNxVHJXTTFGckNVUkxPZVplWnM= (accessed on 4 November 2019).

8. Mengdong Power Wind Power Heating Pilot 3 Years to Reduce Coal Consumption by 68,700 Tons. Polaris Power Network. 7 November 2016. Available online: http://www.sohu.com/a/118288979_131990 (accessed on 7 November 2016).

9. Zhang, X.; Yang, J.H.; Wang, W.Z. Integrated optimal dispatch of a rural micro-energy-grid with multi-energy stream based on model predictive control. Energies 2018, 11, 3439. [CrossRef]

10. Du, L.; Sun, L.; Chen, H.H. Multi-index evaluation of integrated energy system with P2G planning. Electr. Power Autom. Equip. 2017, 37, 110-116.

11. Luo, Y.H.; Yin, Z.X.; Yang, D.S. A new wind power accommodation strategy for combined heat and power system based on bi-directional conversion. Energies 2019, 12, 2458. [CrossRef]

12. Peik-Herfeh, M.; Seifi,H.; Sheikh-El-Eslami, M.K. Decision making of a virtual power plant under uncertainties for bidding in a day-ahead market using point estimate method. Int. J. Elec. Power 2013, 44, 88-98. [CrossRef]

13. Yang, H.M.; Yi, D.X.; Zhao, J.H. Distributed optimal dispatch of virtual power plant based on ELM transformation. Management 2014, 10, 1297-1318. [CrossRef]

14. Zamani, A.G.; Zakariazadeh, A.; Jadid, S. Day-ahead resource scheduling of a renewable energy based virtual power plant. Appl. Energy 2016, 169, 324-340. [CrossRef]

15. Tan, Z.F.; Wang, G.; Ju, L.W. Application of CVaR risk aversion approach in the dynamical scheduling optimization model for virtual power plant connected with wind-photovoltaic-energy storage system with uncertainties and demand response. Energy 2017, 124, 198-213. [CrossRef]

16. Hu, M.C.; Lu, S.Y.; Chen, Y.H. Stochastic programming and market equilibrium analysis of microgrids energy management systems. Energy 2016, 113, 662-670. [CrossRef]

17. Tsao, Y.C.; Thanh, V.V.; Lu, J.C. Multiobjective robust fuzzy stochastic approach for sustainable smart grid design. Energy 2016, 176, 929-939. [CrossRef]

18. Li, Z.M.; Xu, Y. Temporally-coordinated optimal operation of a multi-energy microgrid under diverse uncertainties. Appl. Energy 2019, 240, 719-729. [CrossRef]

19. Ju, L.W.; Tan, Q.L.; Zuo, X.T.; Zhao, R. A risk aversion optimal model for microenergy grid low carbon-oriented operation considering power-to-gas and gas storage tank. Int. J. Energy Res. 2019, 43, 1-20. [CrossRef]

20. Chen, Y.; Wei, W.; Liu, F. Analyzing and validating the economical efficiency of managing a cluster of energy hubs in multi-carrier energy systems. Appl. Energy 2018, 230, 403-416. [CrossRef]

21. Ju, L.W.; Zhao, R.; Tan, Q. A multi-objective robust scheduling model and solution algorithm for a novel virtual power plant connected with power-to-gas and gas storage tank considering uncertainty and demand response. Appl. Energy 2019, 250, 1336-1355. [CrossRef]

22. Wang, G.; Tan, Z.F.; Lin, H.Y. Multi-level market transaction optimization model for electricity sales companies with energy storage plant. Energies 2019, 12, 145. [CrossRef]

23. Liu, F.; Zhang, K.L.; Zou, R.M. Robust LFC strategy for wind integrated time-delay power system using EID compensation. Energies 2019, 12, 3223. [CrossRef]

(C) 2019 by the authors. Licensee MDPI, Basel, Switzerland. This article is an open access article distributed under the terms and conditions of the Creative Commons Attribution (CC BY) license (http://creativecommons.org/licenses/by/4.0/). 